\title{
AN ECONOMIC STUDY OF THE ROLE OF FOOD PROCESSING PLANT FOR SUSTAINABLE DEVELOPMENT IN SHARKIA GOVERNORATE
}

\author{
BAUOMY, TAHANY SALEH MOHAMED and ALAA ALI ABD-ELSALAM NEMA
}

Agricultural Economics Research Institute, ARC, Giza

(Manuscript received 18 February 2016)

\begin{abstract}
A

gricultural manufacturing is one of the most important ways to development agricultural sector where it can increase the added value of many agricultural products and farm income. Also it can a chieve locomotive of sustainable development for several reasons, as convert agricultural products to manufactured goods which can be stord for leng time, and thus it extends the life product and reducing the lost of agricultural crops. The study problem was that small projects of plant Agricultural industrialization faces several problems, the most important of these problems were high production costs and low level of productivity techniques, and consequently decreacing of the marketing revenue of the final product. The study relies on two main sources of data which were published data from governmental agencies and initial data from questionnaire initial data was collected from sample of already productive projects in Sharkia govarnrate and it consisted of 30 observation of each project (the total ware 120 observation). The studied projects were rustic bread, pickles, jam, and mushrooms.
\end{abstract}

\section{The most important results of the study were the following:}

* The total production costs to produce ton of studied industries products were $9074.65,9404.45,12099.55,10284.60$ LE for each prermentioned project respectively.

* The values of the total revenue for the four industries were $12000,12500,15000$ , 17000 LE / ton respectively.

* Net revenues for the four industries were 2925.35, 3095.55, 2900.45, 6715.40 LE / ton respectively.

* Profitability of invested pound was $0.32,0.33,0.24,0.62$ LE / ton for studied projects, respectively.

* Marketing margins per ton of the four studied industries were 9500, 2500, 6000, 8000 LE / ton respectively. 


\section{دراسة اقتصادية لدور التصنيع الغذائي النباتي \\ في التنمية المستدامة بمحافظة الثرقية}

تهاني صالح محمد بيومي يوسف و علاء على عبد السلام نعمه

معه بحوث الاقتصاد الزراعي - مركز البحوث الزراعية

\section{مقدمة}

تعتبر الزر اعة أحد دعائم الاقتصاد القومي في جمهورية مصر العربية فقد

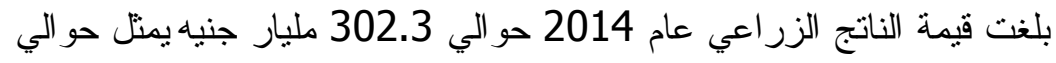
11.79 \% من إجمالي الناتج القومي المصري(7) ، ، وبلغ قيمة الإنتاج النباتي حوالي 165 مليار جنيه تمثل حوالي 58,4\% من إجمالي قيمة الإنتاج الزر اعي • وتتصف الحاصلات الزر اعية النباتية بالموسمية حيث يتم إنتاجها

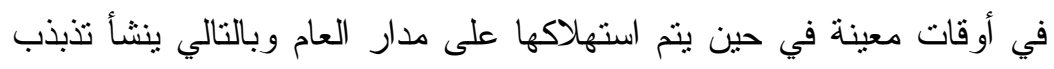

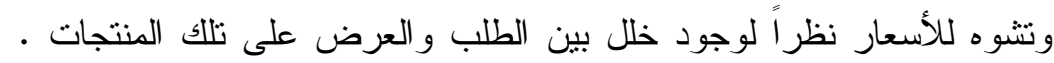

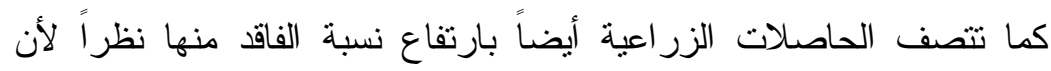

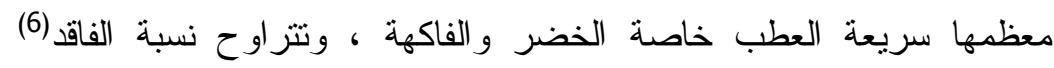

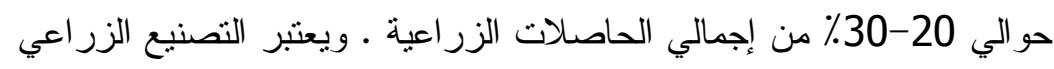

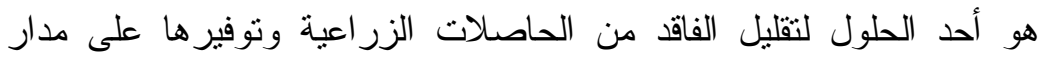
العام، وتهتم الدر اسة بتوضيح دور بعض الصناعات الغذائية النباتية منل الخبز البلدي الفلاحي و الذي تقوم بتصنيعه المر أة الريفية في بيتها وتستخدمه إما في إطعام أسرتها أو تبيعه في أسواق المدن القريبة من قريتها(6) وبالتالي امكانية التعرف علي دور نلاك الصناعات في التتمية المستدامة بريف محافظة الثرقية،

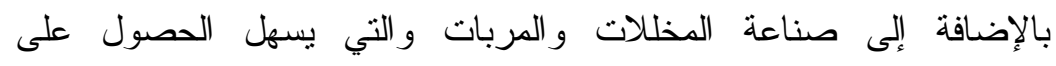

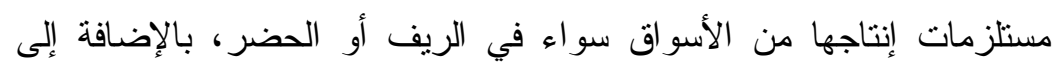

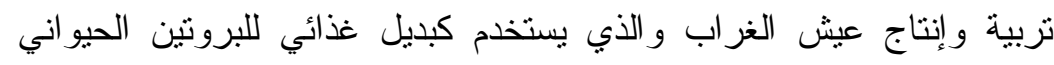

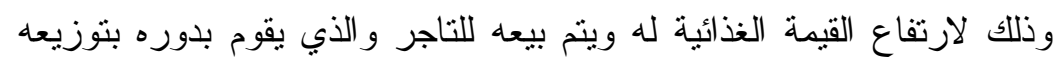

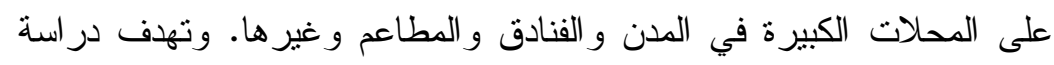

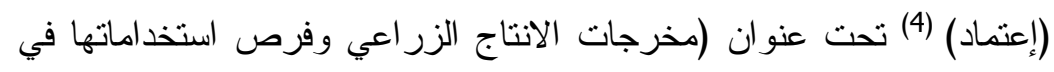

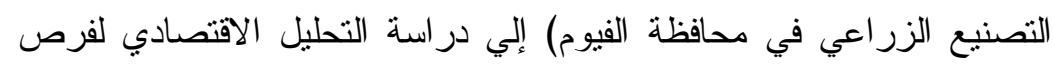

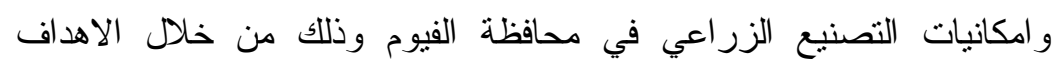
الفرعية التالية : 1- در اسة الوضع الر اهن للانتاج الزر اعي في محافظة الفيوم

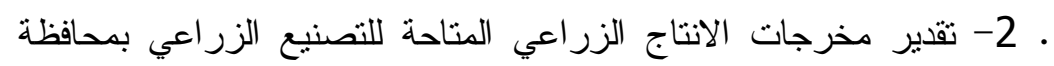


الفيوم • وفي در اسة مقدمة إلى قسم الدراسات الاقليمية بمعهد بحوث الاقتصاد

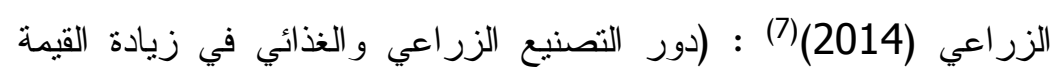

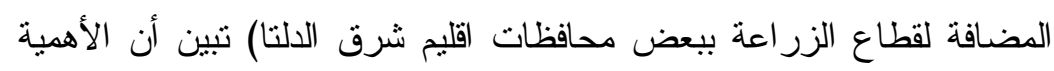

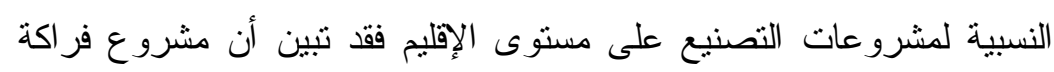
الأرز إحتل المرنبة الأولى يليه مشروع مدشة الحبوب ثم مشروع مشئ مطاحن

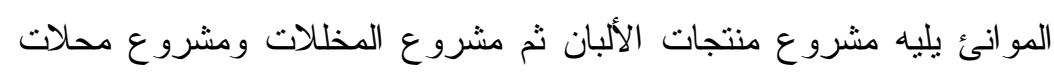
الفول و الطعمية ثم مشروع أفران العيش و المخبز الأفرنجي حيث بلغت الأهمية الهنية النسبية لكل منها حوالي 15,1\%

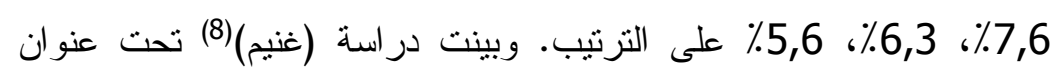

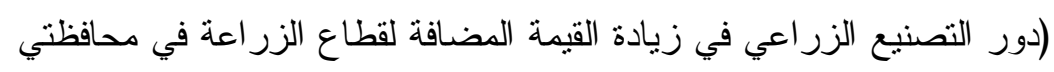
الغربية وكفر الثيخ مشروع فر اكة الارز) أن منوسط كل من إجمالي العائد

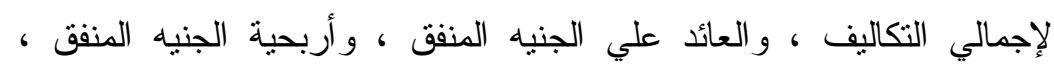

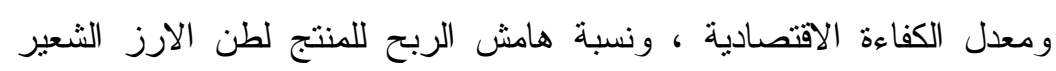

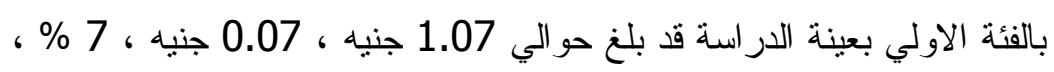

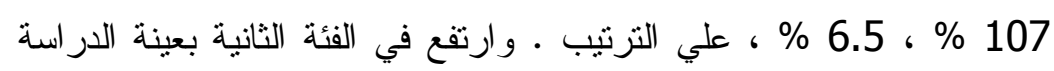

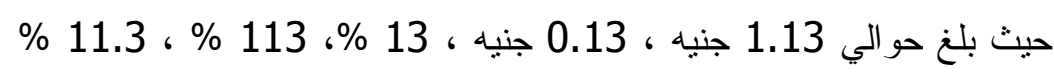

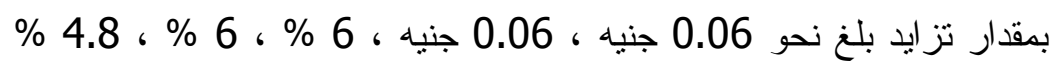

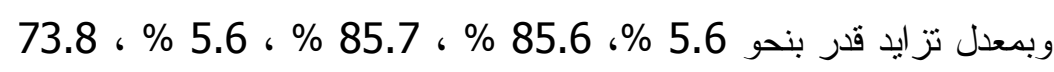

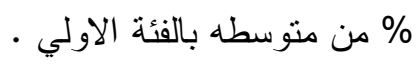

\section{مشكلة الدر اسة}

تكمن مشكلة الدراسة في أن الإنتاج الزر اعي يتم إنتاجه خلال فترات محددة خلد العام في حين أن الن الندار

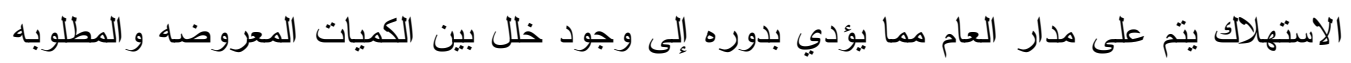

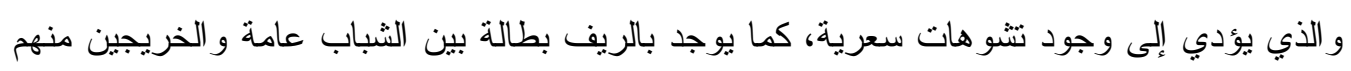

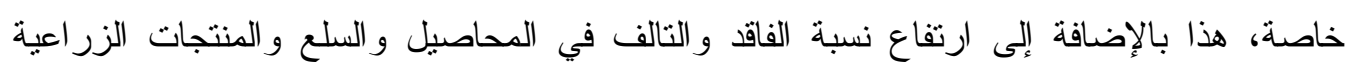
الغذائية .

\section{هدف وأهمية الار اسة}

تهدف الدراسة إلى الارتقاء بمستوى كفاءة التصنيع للمنتجات موضع الدراسة، وذللك من خلال

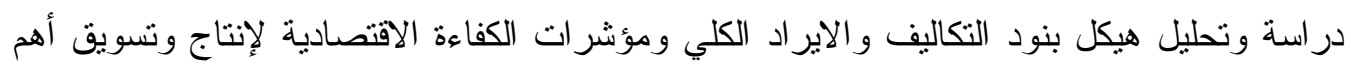
الصناعات الغذائية النباتية. حيث أن التصنيع يساعد علي تخفيض الفاقد الزراعي ونشغيل شباب

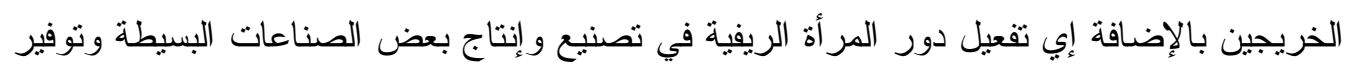

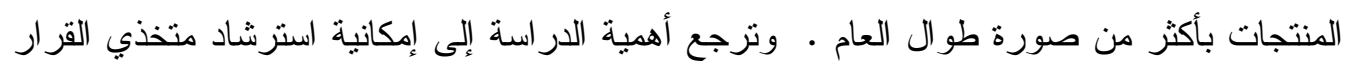

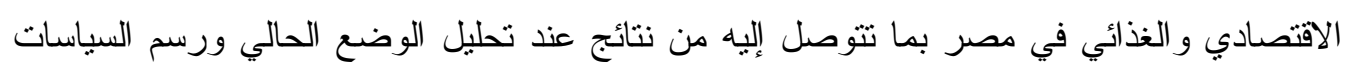


الأسلوب والطريقة البحثية ومصادر البيانات : تعتمد الدراسة على الأسلوبين الوصفي و الكمي في

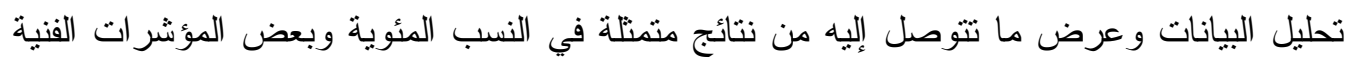

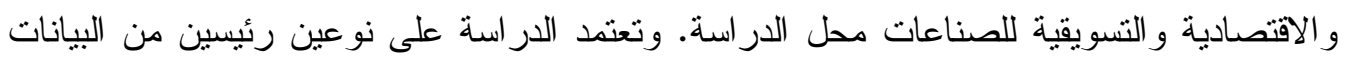

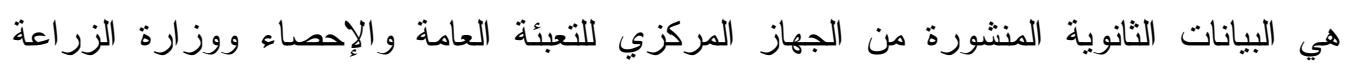

و استصلاح الأر اضي ، وبيانات أولية وذلك من خلال استخدام استمارة استبيان بمحافظة الثرقية .

\section{عينة الدر اسنة فاسن}

نظراً لندرة البيانات المتاحة عن التصنيع الغذائي النباتي فقد نم اختبار عينة ميدانية عمدية لبعض المشروعات القائمة بالفعل بمحافظة الثرقية و التي تقوم بها بعض ربات البيوت وشباب الخريجين،

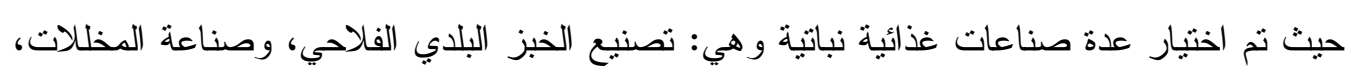

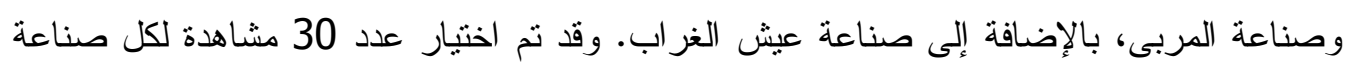

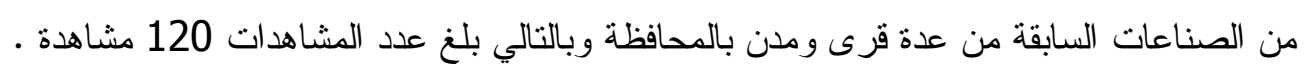

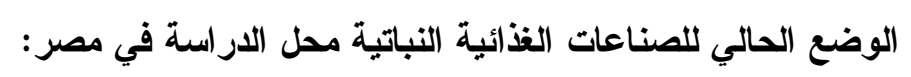

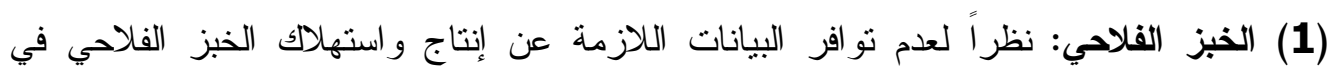

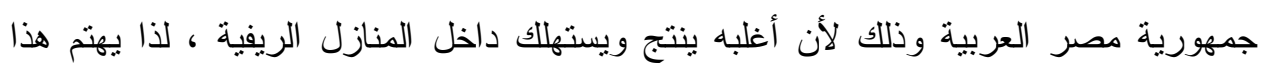

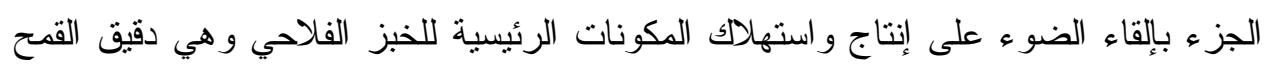

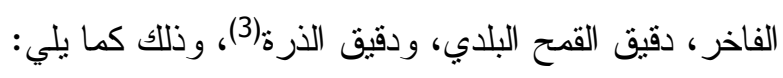

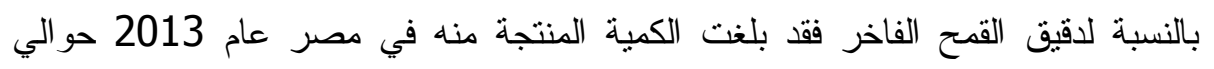
3,35 مليون طن، وبلغت الكمبة المتاحة منه للاستهلاك السنوي حوالي 3,42 ألف طن فن فئن

$$
\text { وبلغ متوسط نصيب الفرد 22,96 كجم/سنة. }
$$

أما بالنسبة لدقيق القمح البلدي فقد بلغت الكمية المنتجة منه في مصر عام 2013 حو الي

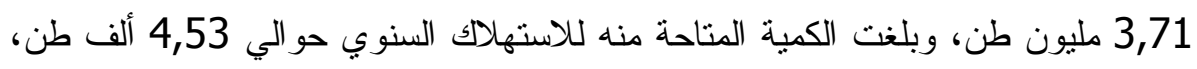

$$
\text { وبلغ متوسط نصيب الفرد 50,4 كجم/سنة. }
$$

أما فيما يتعلق بالدقيق الذرة فقد بلغت الكمية المنتجة منه في مصر عام 2013 حوالي 125 ألف طن، ويستهلاك الإنتاج المحلي بالكامل في الاستهلاك المحلي. المربات والمخلات: بلغت الكمية المنتجة من المربات والمخلات في مصر ولاج عام 2013 حوالي 86,8 ألف طن، 38,9 ألف طن على الترتيب، وتستهلك بالكامل في الاستهلاك المحلي.

عيش الغراب: بلغت الكمية المنتجة من عيش الغراب في مصر (11) عام 2013 حوالي 4,39 ألف طن ويستهلك محلياً، ونتركز مزارع عيش الغراب في محافظات الوجه البحري نظراً

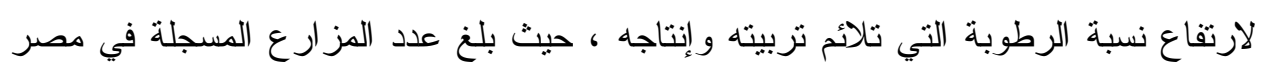

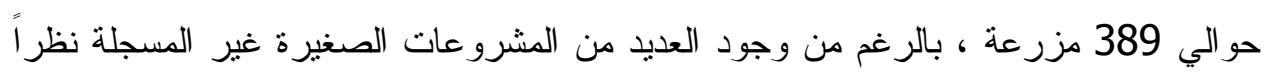

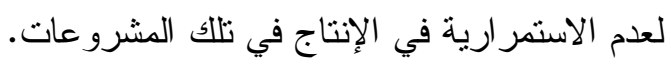




\section{النتائج ومناقشتهها \\ أولاً : هيكل تكاليف الإتتاج والتصنيع للصناعات الغذائية محل الاراسة :}

يشمل هيكل تكاليف الإنتاج و التصنيع للصناعات محل الدراسة تكلفة كلاً من: التكاليف المتنغيرة وتتشمل (مستلزمات الإنتاج، وطاقة التشغيل، والعمل البشري)(3)، بالإضافة إلى التكاليف الثابتة وتتشمل (إهلاك الآلات والأدوات، والقيمة الإيجارية). ويهنم الجزء الآنالي بدر استة البنود السابقة بشيء

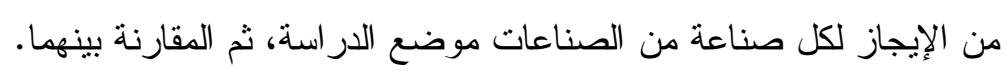

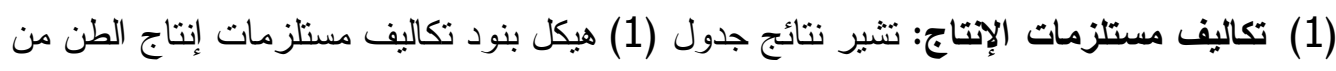

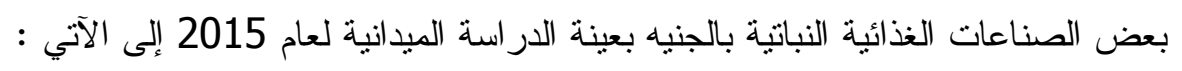

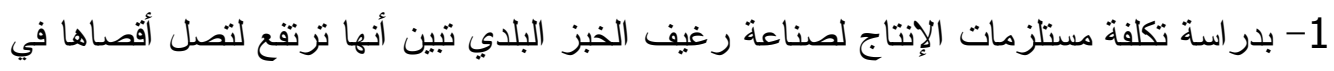

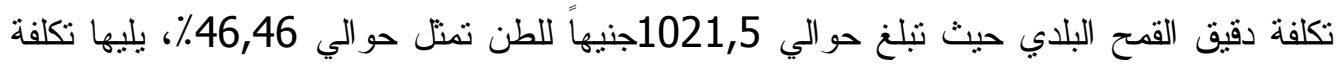
دقيق الذرة وتبلغ 624,25جنيهاً للطن تمنل حو الي 28,4٪، ثم يليها تكلفة دقيق القمح الفاخر وتبلغ حو الي 283,5جنيهاً للطن تمنل حو الي 12,9٪، و انخفضت لتصل أدناها في تكلفة الملح وتبلغ

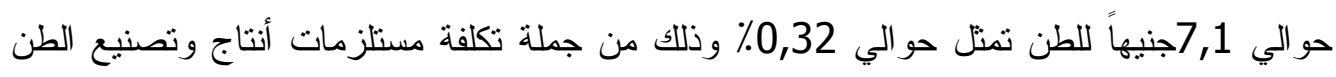
من الخبز البلدي الفلاحي والتي تبلغ حوالي 2198,65 جنيهاً، وهذا يعني أن تكلفة الملح تمثل حو الي 0,7٪ من مثيلتها في تكلفة دقيق القمح البلدي. 2-أما بدراسة تكلفة مستلزمات الإنتاج لصناعة المخلات فقد تنين أنها نرتفع لتصل أقصاها في لفي

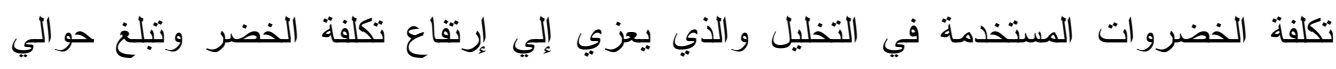
327.35 جنيهاً للطن تمنل حو الي 87,34\% ، يليها تكلفة الأكياس و العبوات المستخدمة في التعبئة

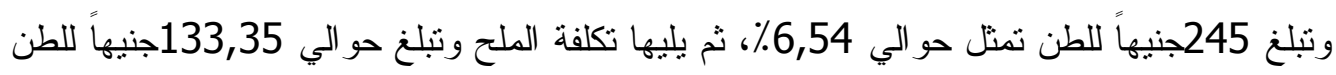
تمثل حو الي 3,56٪ من إجمالي التكلفة ، و انخفضت لتصن أدناها في تكلفة حمض الستريك وتبلغ حو الي6,75 جنيهاً للطن تمنل حو الي 0,18٪ وذللك من جملة تكلفة مستلزمات إنتاج وتصنيع الطن من المخلات و التي تبلغ حوالي 3744,35 جنيهاً ، وهذا يعني أن تكلفة حمض الستريك تمثل

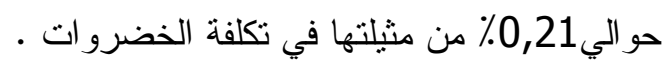
3-أما فيما يتعلق بتكلفة مستلزمات الإنتاج لصناعة المربى فقد تبين أنها ترتفع لتصل أقصاها في تكلفة البرطمانات الزجاجية المستخدمة في تعبئة المنتج حيث تبلغ حوالي 3000 جنيهاً للطن تمثل

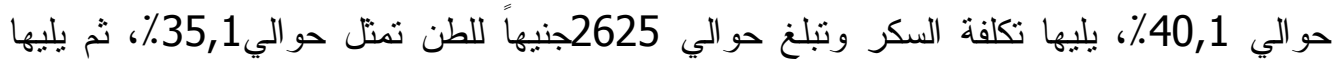
تكلفة الفو اكه و الخضروات المستخدمة في إنتاج المربى وتبلغ حوالي 1750جنيهاً للطن تمنل حو الي

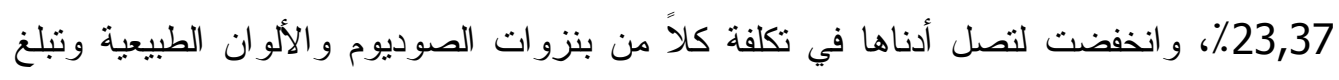
تكلفة كلاً منها على حده حو الي 30 جنيهاً للطن نمنل حو الي 0,4\% وذلك من جملة تكلفة مستلزمات

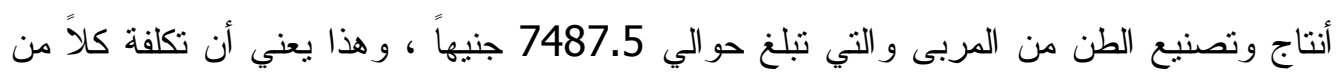
بنزو ات الصوديوم و الألوان الطبيعية على حده تمنل حو الي 0,4٪ من مثيلتها في تكلفة البرطمانات 
جدول (1): هيكل بنود تكاليف مستلزمات إنتاج الطن من بعض الصناعات

الغذائية النباتية بالجنيه بعينة الارسة الميدانية لعام 2015.

\begin{tabular}{|c|c|c|c|c|c|c|c|}
\hline$(\%)$ & $\begin{array}{c}\text { (بالجنيه) } \\
\end{array}$ & سعر الوحدة & الكمبة) & الوحدة & المستلزم & الصناعة & b \\
\hline 12,90 & 283,5 & 3 & 94,5 & كجم & دقيق قمح فاخر & \multirow{7}{*}{ الخناعة } & \multirow{7}{*}{1} \\
\hline 46,46 & 1021,5 & 2,25 & 454 & كجم & دقيق قمح بلاي & & \\
\hline 28,40 & 624,25 & 2,75 & 227 & كجم & دقيق ذرة & & \\
\hline 10,31 & 226,8 & 12 & 18,9 & كجم & حلبة & & \\
\hline 0,32 & 7,1 & 1 & 7,1 & كجم & ملح ( ملح مل ماح & & \\
\hline 1,61 & 35,5 & 5 & $\overline{7,1}$ & كجم & سكر & & \\
\hline 100 & 2198,65 & \multicolumn{2}{|c|}{807,7} & كجم & الإجمالي & & \\
\hline 87,34 & 3270,35 & 2,4 & 1362,64 & كجم & خضرو ات متتو عة & \multirow{7}{*}{ المخلات (1) } & \multirow{7}{*}{2} \\
\hline 1,84 & 69 & 1,5 & 46 & التز & خل طعام & & \\
\hline 0,18 & 6,75 & 2,3 & 2,92 & كجم & حمض الستريك & & \\
\hline 3,56 & 133,35 & 1 & 133,35 & كجم & ملح & & \\
\hline 0,53 & 20 & & - & كجم & كلو ريد صوديوم & & \\
\hline 6,54 & 245 & & - & كجم & أكياس و عبو ات & & \\
\hline 100 & 3744,35 & & & & الإجمالي & & \\
\hline 23,37 & 1750 & 2,5 & 700 & كجم & فو اكه وخضرو ات & \multirow{7}{*}{$\begin{array}{l}\text { المربى(2) صناعة } \\
\text { (2) }\end{array}$} & \multirow{7}{*}{3} \\
\hline 0,40 & 30 & 60 & 0,5 & كجم & بنزوات صوديوم & & \\
\hline 35,06 & 2625 & 5 & 525 & كجم & سكر & & \\
\hline 0,70 & 52,5 & 15 & 3,5 & كجم & ملح ليمون & & \\
\hline 0,40 & 30 & 60 & 0,5 & كجم & ألو ان طبيعية & & \\
\hline 40,07 & 3000 & 0,75 & 4000 & عدد & برطة (250ملنات زجاجية & & \\
\hline 100 & 7487,5 & & & & الإجمالي & & \\
\hline 40,88 & 2400 & 12 & 200 & وحدة وحة & بيئة للتربية & \multirow{6}{*}{ تربية و إنتاج } & \multirow{6}{*}{4} \\
\hline 40,88 & 2400 & 12 & 200 & كجم & تقاوي عيش الغراب & & \\
\hline 4,60 & 270 & 20 & 13,5 & لتز ل & مبيدات فطرية & & \\
\hline 0,85 & 50 & & & عدد & قفاز ات و هيدروميتر & & \\
\hline 12,78 & 750 & 5 & 150 & 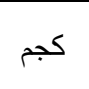 & سأطباق فوم وورق & & \\
\hline 100 & 5870 & & & & الإجمالي & & \\
\hline
\end{tabular}

(1) تشمل المخلات المنتجة: (ليمون، فلفل، خيار، جزر، لفت، قنبيط، وغيرها).

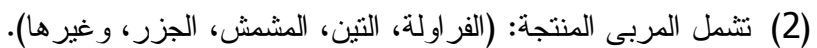

المصدر: حسبت من بيانات عينة الدر اسة الميدانية لعام 2015.

4- و أخيراً بدراسة تكلفة مستلزمات الإنتاج لتربية عبش الغر اب تبين أنها ترتفع لتصل أقصاها في

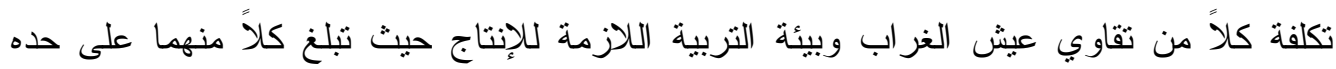
حوالي 2400 جنيهاً للطن تمثل حوالي 40,88٪ ، يليهما تكلفة أطباق الفوم وورق السلوفان لإنان

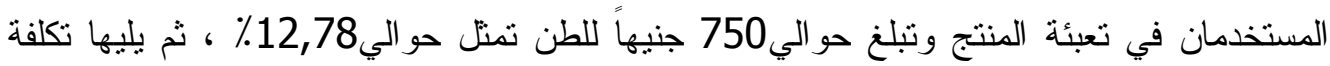


المبيدات الفطرية وتبلغ حو الي270 جنيهاً للطن تمنل حوالي6,6\% ، و وانخفضت لتصل أدناها في تكلفة القفاز ات و الهيدروميتز المستخدم في قياس نسبة الرطوبة بالإضافة إلى الترمومتر المستخدم في

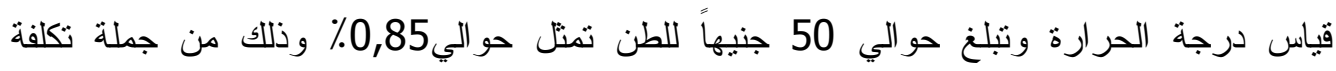

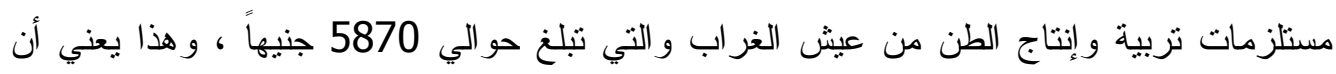

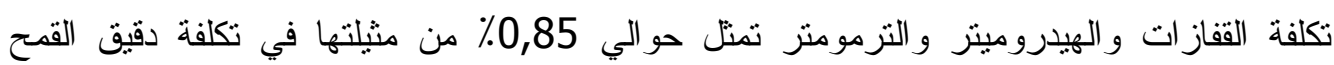
- البلدي

5- وبمقارنة تكلفة مستلزمات الإنتاج و التصنيع للصناعات السابقة تنين أنها ارتفعت لتصل أقصاها

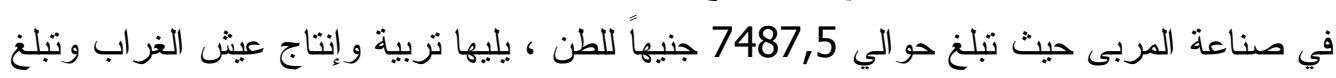

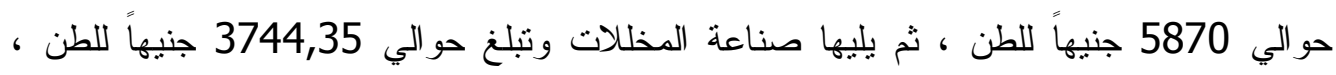
و أقلها في صناعة الخبز الفلاحي وتبلغ حوالي 2198,65 جنيهاً للطن ، و هذا يعني أن تكلفة إنتاج

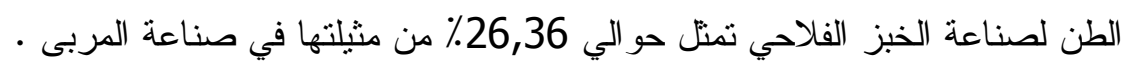
(3) تكاليف طاقة التشغيل :

يتضح من بيانات جدول (2) تكلفة مصادر طاقة التشغيل للصناعات الغذائية النباتية بعينة

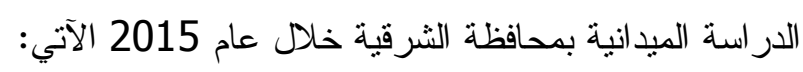
1- بدر اسة تكلفة طاقة النتغيل لصناعة الخبز الفلاحي تبين أنها بلغت أقصاها في تكلفة المخلفات

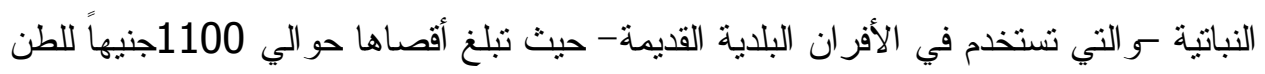

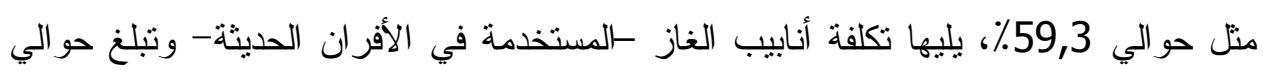

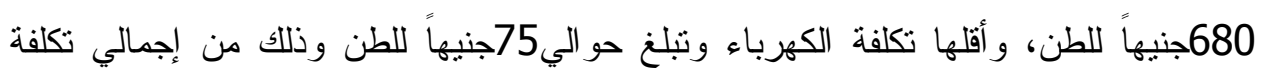

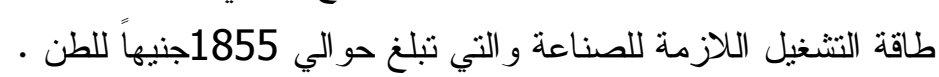
2- أما بدر اسة تكلفة طاقة التشغيل اللازمة لإنتاج المخلات فقد تبين أنها عبارة عن أنابيب الغاز

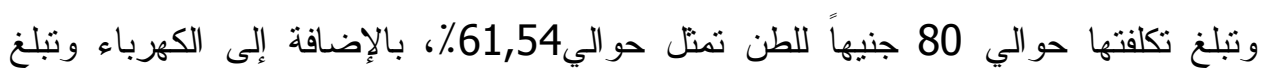
تكلفتها حو الي 50جنيهاً للطن تمثل حوالي 38,46٪ وذللك من إجمالي تكلفة طاقة التشغيل

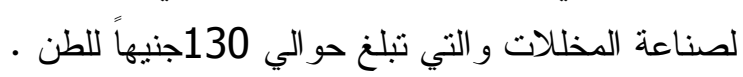
3- أما فيما يتعلق بتكلفة طاقة التشغيل اللازمة لإنتاج المربات فقد تبين أن أعلى تكلفة تتمثل في

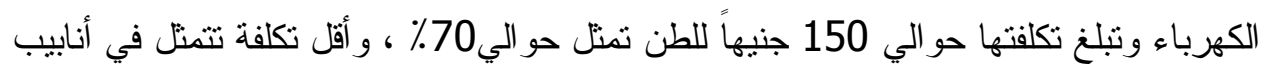

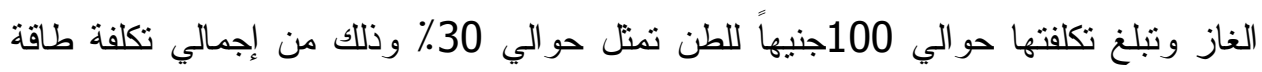

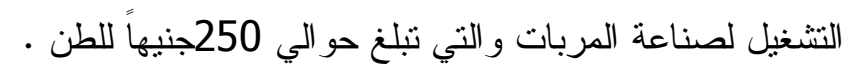
4- و وأخيراً بدر اسة تكلفة طاقة التشغيل اللازمة لإنتاج عيش الغراب فقد تبين أن أعلى تكلفة تتمثل

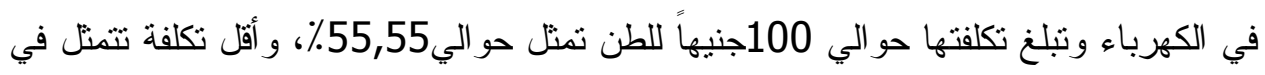

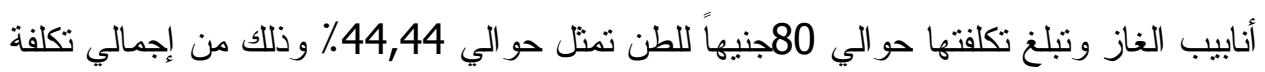
طاقة التشغيل لصناعة المربات و التي تبلغ حو الي 180جنيهاً للطن. 5- بمقارنة تكلفة طاقة التشغيل للصناعات الغذائية الأربعة محل الدر اسة تبين أنها ارتفعت لتصل

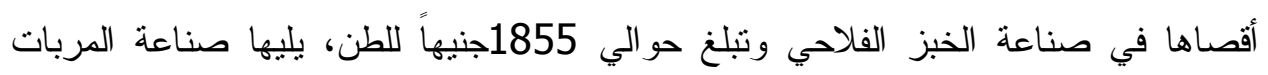


وتبلغ حو الي 250 جنيهاً للطن، ثم يليها نزبية و إنتاج عيش الغراب وتبلغ حوالي 180جنيهاً

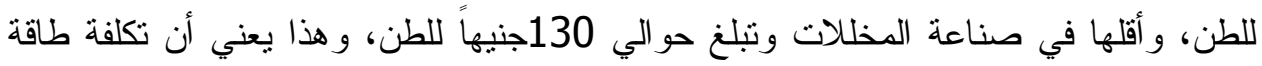
التشغيل لإنتاج طن من المخلات تمنل حو الي 7٪ من مثنيلتها في صناعة الخبز الفلاحي.

جدول (2): تكلفة مصادر طاقة التشغيل للصناعات الغذائية النباتية

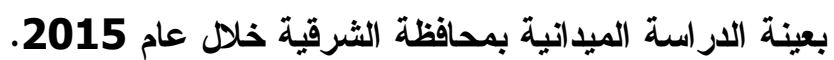

\begin{tabular}{|c|c|c|c|c|c|c|c|}
\hline$(\%)$ & 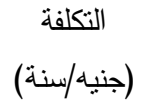 & سعر الوحدة & الكمية & الوحدة & نوع الطاقة & الصناعة & 5 \\
\hline 59,30 & 1100 & 50 & 22 & حمل & نباتية (1) & \multirow{4}{*}{ صناعة الخبز } & \multirow{4}{*}{1} \\
\hline 36,66 & 680 & 20 & 34 & أنبوبة & أنابيب غاز & & \\
\hline 4,04 & 75 & - & - & قيمة & الكهرباء & & \\
\hline 100 & 1855 & - & - & - & الإجمالي & & \\
\hline 61,54 & 80 & 20 & 4 & أنبوبة & أنابيب الغاز & \multirow{3}{*}{ المخلات } & \multirow{3}{*}{2} \\
\hline 38,46 & 50 & - & - & قيمة & الكهرباء & & \\
\hline 100 & 130 & - & - & - & الإجمالي & & \\
\hline 40 & 100 & 20 & 5 & أنبوبة & أنابيب الغاز & \multirow{3}{*}{ المربات } & \multirow{3}{*}{3} \\
\hline 60 & 150 & - & - & قيمة & الكهرباء & & \\
\hline 100 & 250 & - & - & - & الإجمالي & & \\
\hline 44,44 & 80 & 20 & 4 & أنبوبة & أنابيب الغاز & \multirow{3}{*}{ تربية عيش } & \multirow{3}{*}{4} \\
\hline 55,55 & 100 & - & - & قيمة & كهرباء & & \\
\hline 100 & 180 & - & - & - & الإجمالي & & \\
\hline
\end{tabular}

(1) تثمل : (حطب الذرة ، مصاصة القصب، وغيرها) ، و هي تستخدم في الأفران البلدية القديمة . المصدر: حسبت من بيانات عينة الدر اسة الميدانية لعام 2015.

(3) تكلفة العمل البشري: يتضح من البيانات الواردة بالجدول (3) تكلفة العمل البشري للصناعات الغذائية النباتية بعينة الدر اسة الميدانية بمحافظة الثرقية خلال عام 2015 الآتي: 1- بدراسة تكلفة العمل البشري لصناعة الخبز الفلاحي تبين أنها عبارة عن عمالة عائلية ويبلغ

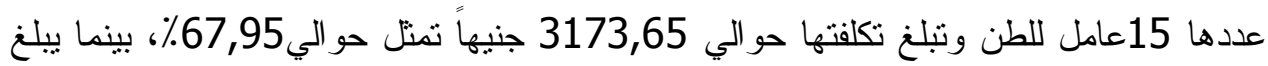

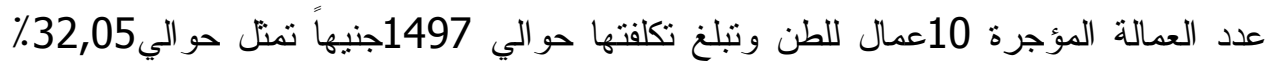

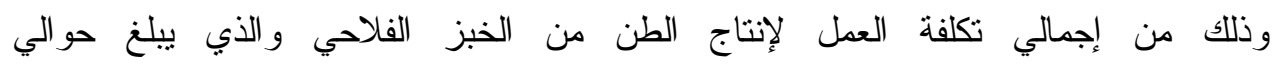
4670,65 منيهاً. 2- أما بدراسة تكلفة العمل البشري لصناعة المخلات فقد تبين أنالعمالة العائلية يبلغ عددها 3عمال للطن وتنلغ تكلفتها حو الي 1000جنيهاً تمثل حوالي 22,22٪، بينما بيلغ عدد العمالة المؤجرة

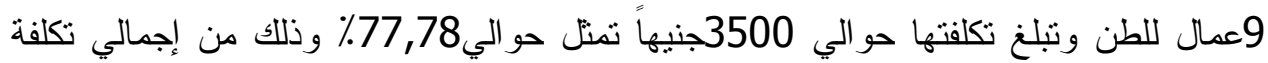
العمل لإنتاج الطن من المخلات و الذي يبلغ حو الي 4500جنيهاً. 
3- أما فيما يتعلق بتكلفة العمل البشري لصناعة المرباتفقد تبين أنالعمالة العائلية يبلغ عددها 10عمال للطن وتبلغ تكلفتها حو الي 1400جنيهاً تمثل حو الي 28,57٪، بينما يبلغ عدد العمالة

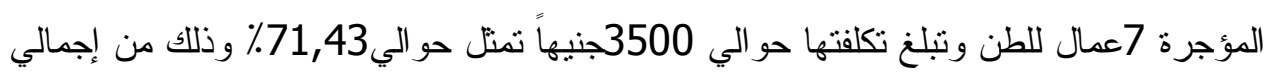
تكلفة العمل لإنتاج الطن من المربات و الذي ييلغ حو الي

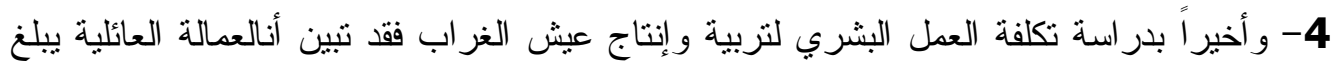

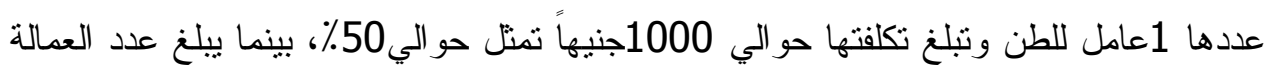

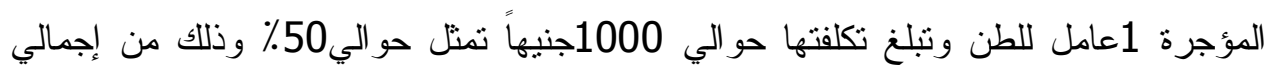
تكلفة العمل لإنتاج الطن من عيش الغر اب و الذي يبلغ حو الي 2000جنيهاً.

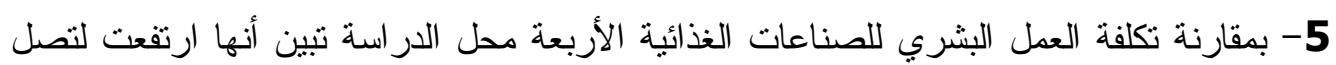

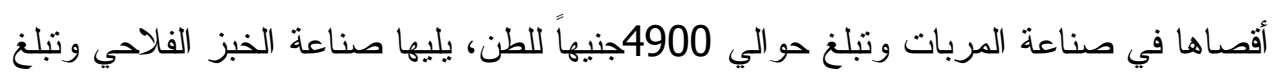

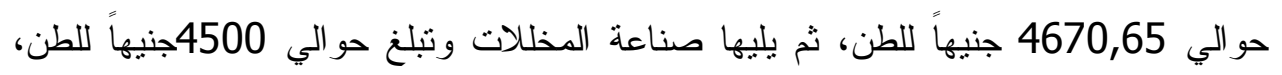

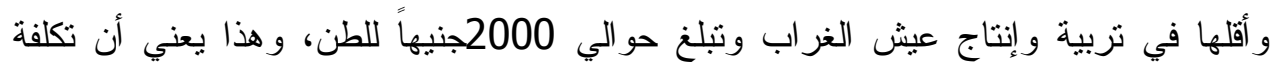

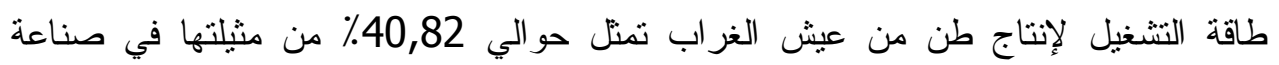
المربات.

\section{جدول (3) : تكلفة العمل البشري للصناعات الغذائية النباتية}

\section{بعينة الاراسة الميدانية بمحافظة الثرقية خلا عام 2015.}

\begin{tabular}{|c|c|c|c|c|c|c|c|}
\hline \multirow{2}{*}{ إلجمالي } & \multicolumn{2}{|c|}{ العمالة المؤجرة } & \multicolumn{2}{|c|}{ العمالة العائلية } & \multirow{2}{*}{ العاملين } & \multirow[b]{2}{*}{ الصناعة } & \multirow[b]{2}{*}{ ? } \\
\hline & تكلفة العمالة & 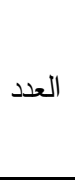 & تكلفة العمالة & 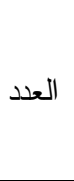 & & & \\
\hline 4670,65 & 1497 & 10 & 3173,65 & 15 & 25 & صناعة الخبز & 1 \\
\hline 4500 & 3500 & 9 & 1000 & 3 & 12 & صناعة المخلات & 2 \\
\hline 4900 & 3500 & 7 & 1400 & 3 & 10 & صناعة المربات & 3 \\
\hline 2000 & 1000 & 1 & 1000 & 1 & 2 & تربية عيش الغر اب & 4 \\
\hline
\end{tabular}

المصدر: حسبت من بيانات عينة الدراسة الميدانية لعام 2015.

(4) تكلفة إهلاك الآلات والمعدات: يتضح من البيانات الواردة بالجدول (4) تكلفة إهلاك الآلات و المعدات للصناعات الغذائية النباتية بعينة الدراسة الميدانية بمحافظة الثرقية خلال عام 2015 الآتي: 1-بدر اسة تكلفة إهلاك الآلات و المعدات لصناعة الخبز الفلاحي تبين أنها ارتفعت لتصل أقصاها تكلفة إهلاك الأفران الصاج وتبلغ حوالي 40جنيهاً للطن تمنل حوالي 50٪، يليها تكلفة إهلاك

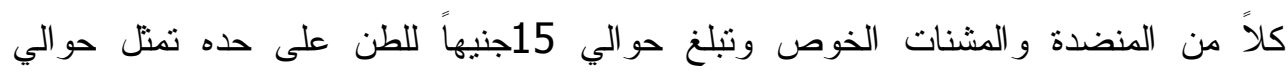


18,75\%، ثم يليهما تكلفة كلاً من و عاء العجين الفخار و آلة الخبيز وتبلغ لكلاً منهها على حده حو الي 5جنيهات تمنل حو الي 6,25٪؛ وذللك من إجمالي إهلاك الآلات و المعدات لصناعة ولهن الخبز

$$
\text { البلدي وتبلغ حو الي 80جنيهاً للطن. }
$$

2-أما بدراسة تكلفة إهلاك الآلات و المعدات لصناعة المخلات تبين أن أقصاها تكلفة إهلاك

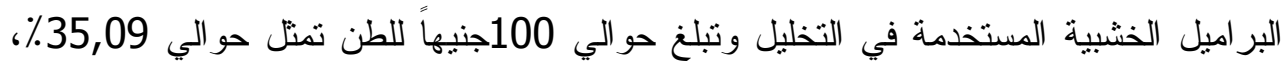

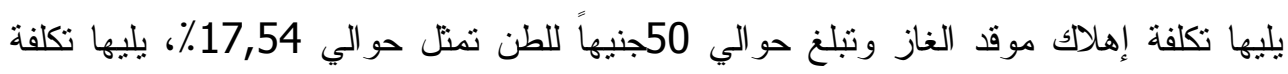

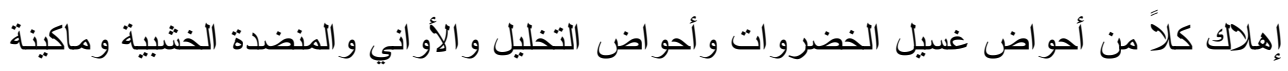

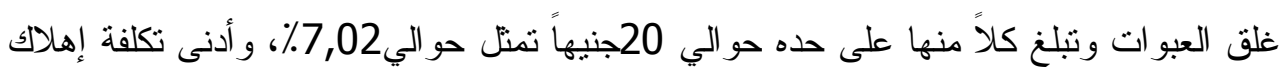

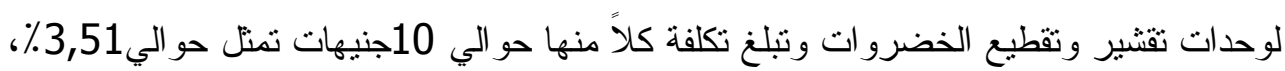
وذلك من إجمالي إهلاك الآلات و الأدوات وتبلغ حو الي 250 جنيهاً للطن. 3 - أما فيما يتعلق بتكلفة إهلاك الآلات والأدوات لصناعة المربات فقد تنين أن أقصاها تكلفة إهلاك الفريزر المستخدم في حفظ الفو اكه و الخضروات الموسمية حتى تكون متاحة طو ال العام وتبلغ حو الي

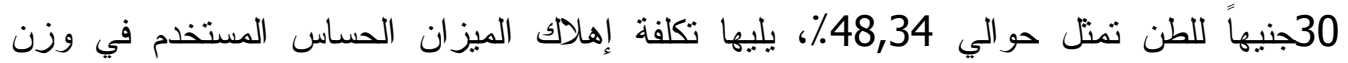
المكونات وتبلغ حو الي 10جنيهاً للطن تمنل حو الي 11,11٪، يليها تكلفة إهلاك كلاً من موقد الغاز

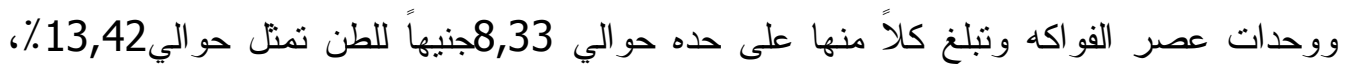
و أدنى تكلفة إهلاك لكلاً من أحو اض غسيل الفو اكه ووحدات تقشير وتقطيع الفو اكه وتبلغ كلاً منها

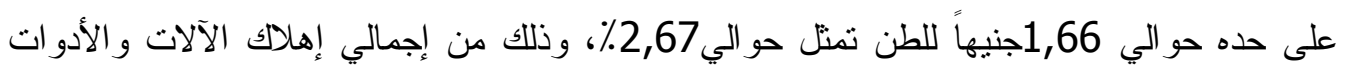

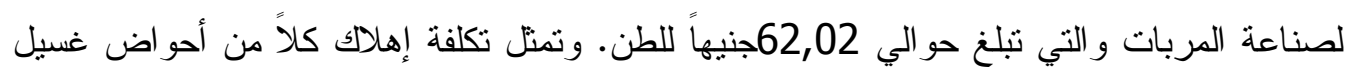
الفو اكه ووحدات تقشير وتقطيع الفو اكه حو الي 5,53٪ من مثنيتها في تكلفة إهلاك الفريزر . 4 - وأخيراً بالنسبة بتكلفة إهلاك الآلات والأدوات لنربية وإنتاج عيش الغراب فقد تنبين أن أقصاها

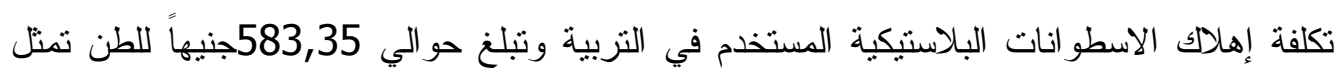

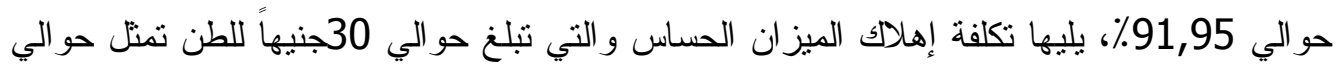

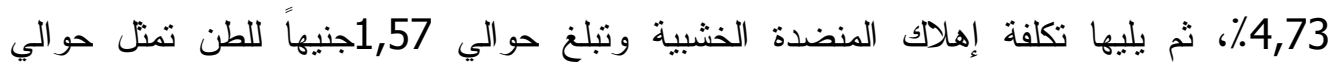

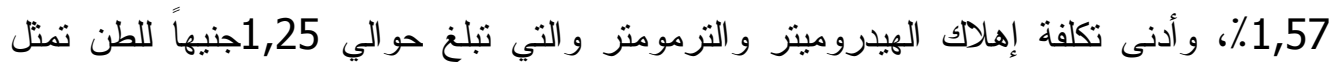

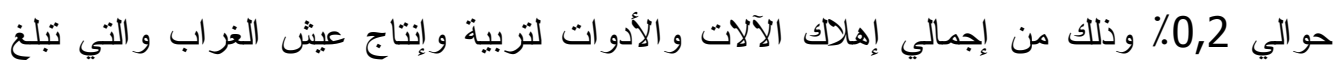

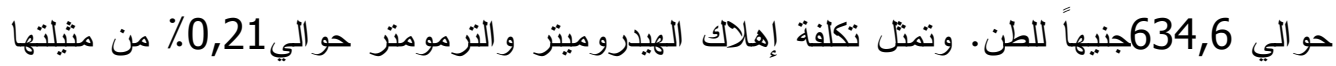
في تكلفة إهلاك الاسطو انات البلاستيكية. 5 - بمقارنة تكلفة إهلاك الآلات و الأدوات للصناعات الغذائية محل الدراسة تبين أنها ارتفعت لتصل أقصاها في نربية و إنتاج عيش الغراب وتبلغ حو الي 634,6جنيهاً للطن، يليها صناعة المخلات

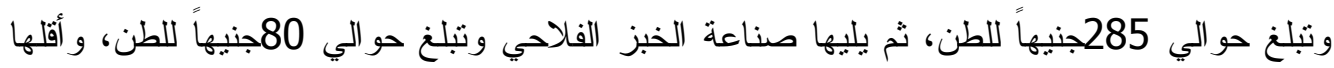
في صناعة المربات وتبلغ حو الي 62,06جنيهاً للطن، وهذاعن يعني أن تكلفة طاقة التشغيل لإنتاج الطن

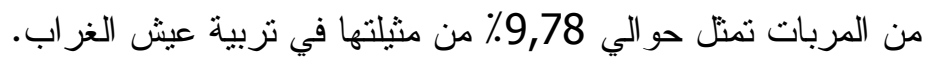


جدول (4): تكلفة إهلاك الآلات والمعدات للصناعات الغذائية النباتية

بعينة الدراسة الميدانية بمحافظة الثرقية خلا علد عام 2015.

\begin{tabular}{|c|c|c|c|c|c|c|c|c|}
\hline$(\%)$ & (بكلفة الإهلالاك) & الالافتر اضي & $\begin{array}{c}\text { الثر اءة } \\
\text { (بالجنيه) }\end{array}$ & $\begin{array}{c}\text { (الوحدة: } \\
\text { (بالجنيه) }\end{array}$ & الوحدات & الآلة/المعدة & الصناعة & s \\
\hline 6,25 & 5 & 10 & 50 & 50 & 1 & و فاء عجين & \multirow{6}{*}{ الفناعة } & \multirow{6}{*}{1} \\
\hline 6,25 & 5 & 3 & 15 & 15 & 1 & الة خبيز & & \\
\hline 18,75 & 15 & 10 & 150 & 150 & 1 & المنضدة & & \\
\hline 50 & 40 & 10 & 400 & 400 & 1 & فرن صاج & & \\
\hline 18,75 & 15 & 5 & 125 & 25 & 5 & مشنات خوص & & \\
\hline 100 & 80 & - & 610 & & & الإجمالي & & \\
\hline 35,09 & 100 & 15 & 1500 & 150 & 10 & وزب اميل خثبّ & \multirow{10}{*}{ المخلات } & \multirow{10}{*}{2} \\
\hline 7,02 & 20 & 15 & 300 & 150 & 2 & الخضراض غسيل & & \\
\hline 7,02 & 20 & 15 & 300 & 150 & 2 & أحو اض التخليل & & \\
\hline 7,02 & 20 & 10 & 200 & 50 & 4 & الخض بعض لسلق & & \\
\hline 17,54 & 50 & 10 & 500 & 500 & 1 & موقد غاز & & \\
\hline 3,51 & 10 & 10 & 100 & 10 & 10 & والخضات تقطيع & & \\
\hline 3,51 & 10 & 10 & 100 & 10 & 10 & والخضروات تقشير & & \\
\hline 7,02 & 20 & 15 & 300 & 150 & 2 & كنضدة خشب & & \\
\hline 7,02 & 20 & 10 & 200 & 200 & 1 & ماكينة غلق & & \\
\hline$\frac{5,25}{100}$ & $\begin{array}{c}\frac{15}{285} \\
\end{array}$ & 10 & 150 & 150 & 1 & الإجمالى مبزان & & \\
\hline 48,34 & 30 & 10 & 3600 & 1800 & 2 & لحفظيز الفو كبير & \multirow{7}{*}{ المربات } & \multirow{7}{*}{3} \\
\hline 2,67 & 1,66 & 15 & 150 & 150 & 1 & الحو اضاكهة لغسيل & & \\
\hline 2,67 & 1,66 & 10 & 100 & 10 & 10 & وتقثيرات الفقطيع & & \\
\hline 13,42 & 8,33 & 10 & 1000 & 500 & 2 & موقد غاز & & \\
\hline 13,42 & 8,33 & 10 & 1000 & 250 & 4 & وحدات عصر اكه & & \\
\hline 3,35 & 2,08 & 10 & 250 & 50 & 5 & أو اني طربي & & \\
\hline$\frac{16,11}{100}$ & $\begin{array}{c}10 \\
62,06\end{array}$ & 10 & $\frac{1200}{6310}$ & 1200 & 1 & ميز الإنمالي حساس & & \\
\hline 91,95 & 583,35 & 6 & 7000 & 70 & 100 & إبطظو انات & \multirow{7}{*}{ الغربش } & \multirow{7}{*}{4} \\
\hline 1,57 & 10 & 10 & 400 & 200 & 2 & منضدة خشب & & \\
\hline 0,79 & 5 & 10 & 200 & 100 & 2 & مناشر خشب & & \\
\hline 0,79 & 5 & 10 & 250 & 250 & 1 & موقد غاز & & \\
\hline 4,73 & 30 & 10 & 1200 & 1200 & 1 & ميزان حساس & & \\
\hline 0,20 & 1,25 & 10 & 50 & 25 & 2 & و هيدروميتزر & & \\
\hline 100 & 634,60 & & & 1525 & & الإجمالي & & \\
\hline
\end{tabular}


(5) إجمالي تكاليف الصناعات الغذائية محل الدراسة: تشير نتائج الجدول (5) إجمالي تكاليف الصناعات الغذائية النباتية بالجنيه/ سنة بعينة الدراسة الميدانية بمحافظة الثرقية خلال عام 2015 إلى الآتي: 1- بدر اسة التكاليف الإنتاجية لصناعة الخبز الفلاحي تنين أن جملة التكاليف المتغيرة تبلغ حوالي

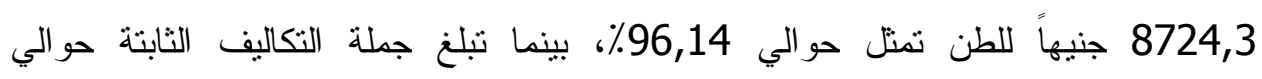

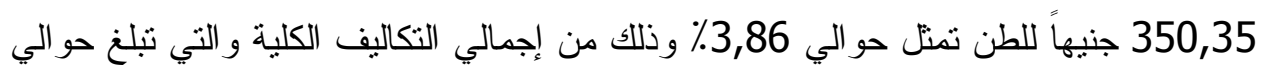
9074,65 جنيهاً للطن. 2- أما بدر اسة التكاليف الإنتاجية لصناعة المخلات تبين أن جملة التكاليف المتغيرة تبلغ حوالي

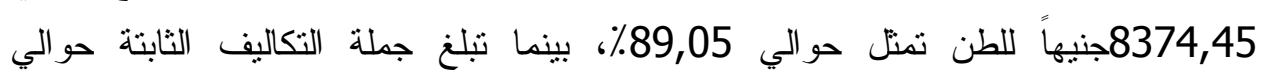

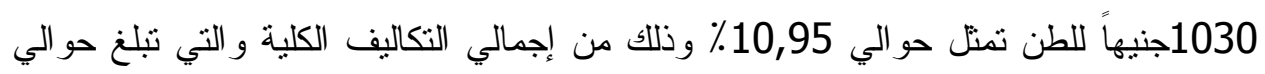
9404,45 جنيهاً للطن. 3- أما فيما يتعلق بالتكاليف الإنتاجية لصناعة المربات تبين أن جملة التكاليف المتغيرة تبلغ حوالي

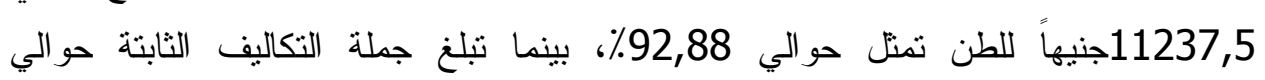

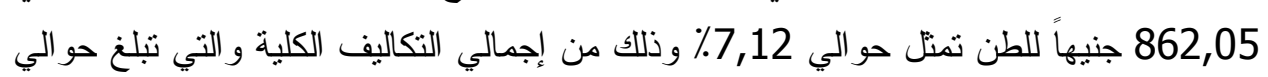
12099,55

4- ـ و أخيراً بالنسبة للتكاليف الإنتاجية لتربية و إنتاج عيش الغراب تنين أن جملة التكاليف المتغيرة تبلغ حو الي 8050 جنيهاً للطن تمثل حو الي 78,27٪، بينما تبلغ جملة التكاليف الثابتة حوالي تئي 2234,6 حو الي 10284,6جنيهاً للطن. 5 - بمقارنة التكاليف الإنتاجية الكلية للصناعات الأربعة محل الدراسة تبين أن أقصاها في تكاليف

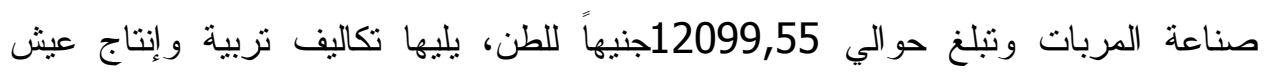
الغر اب وتبلغ حو الي 10284,6جنيهاً للطن، ثم يليها تكاليف صناعة المخلات وتبلغ حو الي

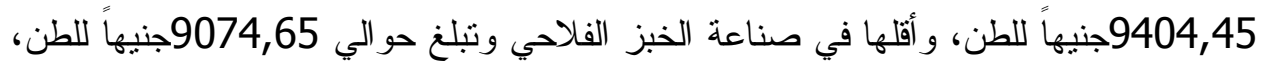
وبذلك تمثل التكاليف الكلية لصناعة الخبز الفلاحي حوالي 75٪ من مثيلتها في صناعة المربات. 
جدول (5): إجمالي تكاليف الصناعات الغذائية النباتية بالجنيه/سنة بعينة

الار اسة الميدانية بمحافظة الشرقية خلال عام 2015.

\begin{tabular}{|c|c|c|c|c|c|}
\hline$(\%)$ & للكمية المصنعة & بنود التكلفة & & الصناعة & s \\
\hline 24,23 & 2198,65 & تكاليف مستلزمات الإنتاج & \multirow{4}{*}{ التكاليف } & \multirow{8}{*}{ صناعة الخبز } & \multirow{8}{*}{1} \\
\hline 20,44 & 1855 & تكلفة طاقة التتشغيل & & & \\
\hline 51,47 & 4670,65 & تكلفة العمل البشري & & & \\
\hline 96,14 & 8724,30 & جملة التكاليف المتغيرة & & & \\
\hline 0,55 & 50,35 & تكلفة إهلاك أدو ات ومعدات & \multirow{3}{*}{ التكاليف } & & \\
\hline 3,31 & 300 & تكلفة الإيجار & & & \\
\hline 3,86 & 350,35 & جملة التكاليف الثابتة & & & \\
\hline 100 & 9074,65 & \multicolumn{2}{|l|}{ إجمالي التكاليف الكلية } & & \\
\hline 39,81 & 3744,45 & تكاليف مستلزمات الإنتاج & \multirow{4}{*}{ التكاليف } & \multirow{8}{*}{ المخلات } & \multirow{8}{*}{2} \\
\hline 1,38 & 130 & تكلفة طاقة التشتيل & & & \\
\hline 47,85 & 4500 & تكلفة العمل البشري & & & \\
\hline 89,05 & 8374,45 & جملة التكاليف المتغيرة & & & \\
\hline 2,44 & 230 & تكلفة إهلاك أدو ات ومعدات & \multirow{3}{*}{ التكاليف } & & \\
\hline 8,51 & 800 & تكلفة الإيجار & & & \\
\hline 10,95 & 1030 & جملة التكاليف الثابتة & & & \\
\hline 100 & 9404,45 & \multicolumn{2}{|l|}{ إجمالي التكاليف الكلية } & & \\
\hline 61,88 & 7487,5 & تكاليف مستلزمات الإنتاج & \multirow{4}{*}{ التكاليف } & \multirow{8}{*}{ صناعة المربات } & \multirow{8}{*}{3} \\
\hline 2,07 & 250 & تكلفة طاقة التشغيل & & & \\
\hline 28,93 & 3500 & تكلفة العمل البشري & & & \\
\hline 92,88 & 11237,5 & جملة التكاليف المتغيرة & & & \\
\hline 0,51 & 62,05 & تكلفة إهلاك أدوات ومعدات & \multirow{3}{*}{ التكاليف } & & \\
\hline 6,61 & 800 & تكلفة الإيجار & & & \\
\hline 7,12 & 862,05 & جملة التكاليف الثابتة & & & \\
\hline 100 & 12099,55 & \multicolumn{2}{|l|}{ إجمالي التكاليف الكلية } & & \\
\hline 57,07 & 5870 & تكاليف مستلزمات الإنتاج & \multirow{4}{*}{ التكاليف } & \multirow{8}{*}{ تربية عبش الغراب } & \multirow{8}{*}{4} \\
\hline 1,75 & 180 & تكلفة طاقة التشغيل & & & \\
\hline 19,45 & 2000 & تكلفة العمل البشري & & & \\
\hline 78,27 & 8050 & جملة التكاليف المتغيرة & & & \\
\hline 6,17 & 634,60 & تكلفة إهلاك أدوات ومعدات & \multirow{3}{*}{ التكاليف } & & \\
\hline 15,56 & 1600 & تكلفة الإيجار & & & \\
\hline 21,73 & 2234,60 & جملة التكاليف الثابتة & & & \\
\hline 100 & 10284,60 & \multicolumn{2}{|l|}{ إجمالي التكاليف الكلية } & & \\
\hline
\end{tabular}

المصدر: حسبت من بيانات عينة الدرلسة الميدانية لعام 2015. 
ثانياً: هيكل الإيراد الكلي للصناعات الغذائية النباتية محل الدراسة: تشير بيانات الجدول (6) إلى أن قيمة إيرادات الطن من المنتجات النهائية للصناعات محل

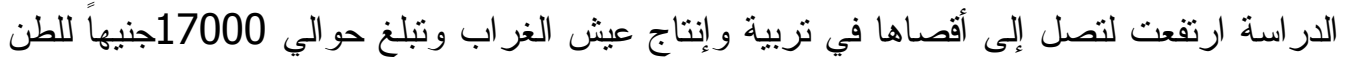

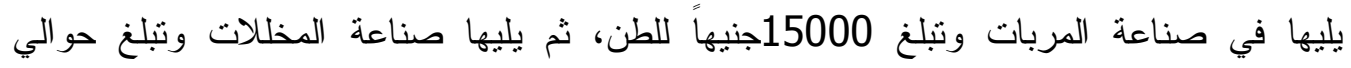

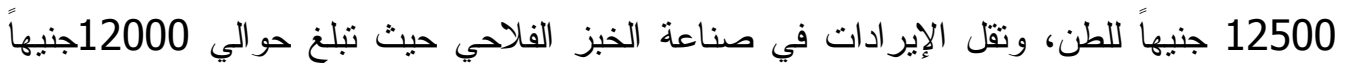
للطن، وتمنل الإير ادات لصناعة الخبز الفلاحي حو الي 70,6٪ من مثيلتها في صناعة المربات. جدول (6): إيراد بيع منتجات الصناعات الغذائية النباتية

بعينة الاراسة الميدانية بمحافظة الثرقية خلات عام 2015.

\begin{tabular}{|c|c|c|c|c|c|}
\hline قيمة الناتج (بالجنيه) & سعر الوحدة & الكمية المنتجة & المنتج & الصناعة & s \\
\hline 12000 & 12 & 1000 & رغيف خبز & صناعة الخبز الفلاحي & 1 \\
\hline 12500 & 12,5 & 1000 & مخلات متتو عة & صناعة المخللات & 2 \\
\hline 15000 & 15 & 1000 & 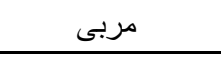 & صناعة المربات & \\
\hline 17000 & 17 & 1000 & فطر عبش الغر اب & صناعة عبش الغراب & 3 \\
\hline
\end{tabular}

المصدر: حسبت من بيانات عينة الدر اسة الميدانية لعام 2015.

ثالثاً: مؤشرات الكفاءة الاقتصادية للإنتاج و التصنيع:

تتثير بيانات الجدول (7) مؤشرات الكفاءة الاقتصادية للصناعات الغذائية النباتية (جنيه/طن) بعينة الدر اسة الميدانية بمحافظة الثرقية خلال عام 2015 إلى مؤشرات الكفاءة الاقتصادية(6) تشمل

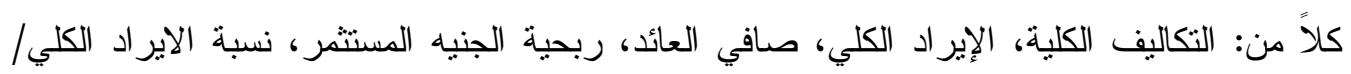
التكاليف الكلية، حافز المنتج (\%). وفي الأجزاء السابقة تمت الإشارة إلى كلاً من التكاليف الكلية و الإير اد الكلي، ويهنم الجزء التالي بمقارنة باقي المؤشرات الاقتصادية بين الصناعات الغذائية النباتية

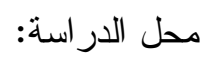

(1) صافي العائد: من الجدول يتضح أن صافي العائد بلغ أقصاه في نربية عيش الغراب ويبلغ

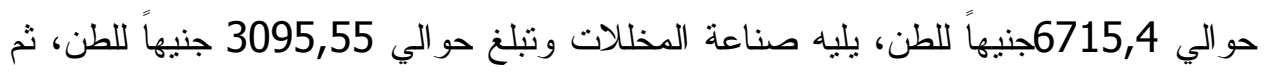

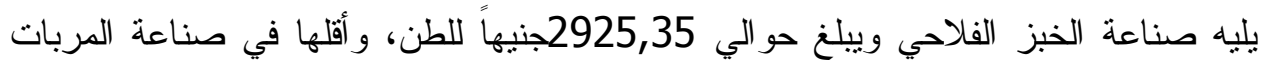
وتبلغ حو الي 2900,45 جنيهاً للطن. (2) ربحية الجنيه المستثمر: من الجدول يتبين أن ربحية الجنيه المستثر بلغ أقصاه في تربية

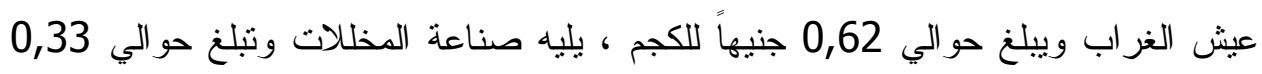

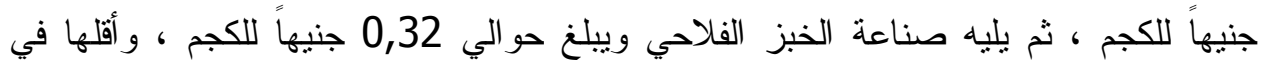
صناعة المربات وتبلغ حوالي (3) نسبة الإيرادات الكلية/ التكاليف الكلية: نتير نتائج الجدول إلى أن نسبة الإيرادات الكلية/التكاليف الكلية بلغ أقصاه في عيش الغراب حيث بلغ حوالي 1.65 جنيه، يليه صناعة 
المخلات حيث بلغ حو الي 1.33 جنيه، ثم يليه صناعة الخبز البلاي حيث بلغ حو الي 1.33

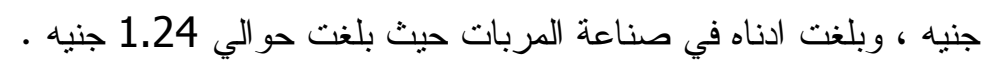
(4) حافز المنتج : من البيانات الواردة الجدول يتضح أن حافز المنتج قد ارتفع ليصل اقصاه في

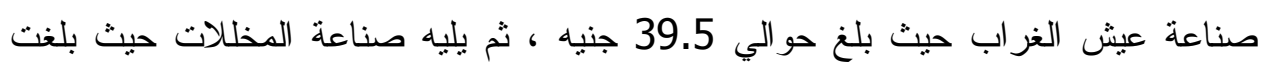

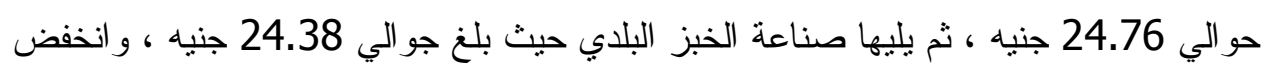

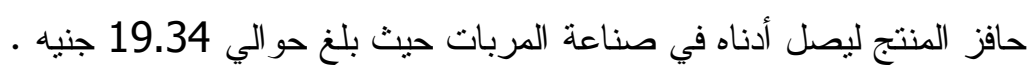

جدول (7) : مؤشرات الكفاءة الاقتصادية للصناعات الغذائية النباتية

بعينة الاراسة الميدانية بمحافظة الشرقية خلا علد عام 2015.

\begin{tabular}{|c|c|c|c|c|}
\hline عيش الغراب & 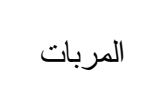 & المخلاتات & البلدي & المؤشر \\
\hline 10284.60 & 12099.55 & 9404.45 & 9074.65 & التكاليف الكلية للطن بالجنيه \\
\hline 17000 & 15000 & 12500 & 12000 & الإير اد الكلي للطن بالجنيه \\
\hline 6715.40 & 2900.45 & 3095.55 & 2925.35 & صافي العائد للطن بالجنيه(1) \\
\hline 0.62 & 0.24 & 0.33 & 0.32 & ربحية الجنيه المستثر بالجنيه(2) \\
\hline 1.65 & 1.24 & 1.33 & 1.32 & نسبة الاير اد الكلي/ التكاليف الكلية \\
\hline 39.50 & 19.34 & 24.76 & 24.38 & حافز المنتج (٪)(4) \\
\hline
\end{tabular}

(1) صافي العائد= العائد الكلي - إجمالي تكاليف التصنيع، (2) ربحية الجنيه المستتر = صافي العائد ؛ إجمالي تكاليف

$$
\begin{aligned}
& \text { (3) نسبة الإير ادات/التكاليف الكليف = الإير ادات الكلية بالجنيه/ التكاليف الكلية بالجنيه. } \\
& \text { (4) حافز المنتج (\%) = صافي العائد للطن بالجنيه/ سعر بيع الطن بالجنيه. } \\
& \text { المصدر: حسبت من بيانات عينة الدر اسة الميدانية لعام } 2014 .
\end{aligned}
$$

رابعاً: مؤشرات الكفاءة التسويقية(1) للصناعات الغذائية محل الار اسة: يتضح من بيانات الجدول (8) مؤشرات الكفاءة التسويقية للصناعات الغذائية النباتية بعينة الدر اسة المبدانية بمحافظة الثرقية خلا عام 2015 أن مؤشرات الكفاءة التسويقية تشمل كلاً من:

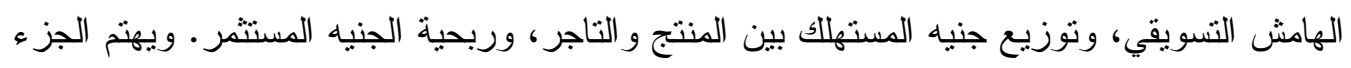
التالي بمقارنة نلك المؤشر ات بين الصناعات الغذائية النباتية محل الدر واسة بشيء من الإيجاز :

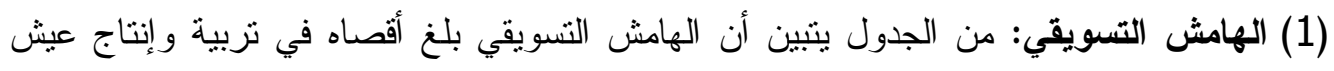

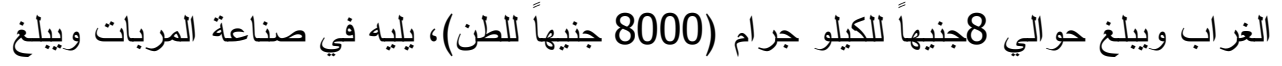

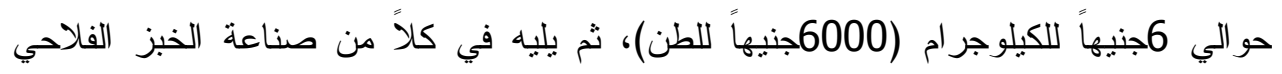

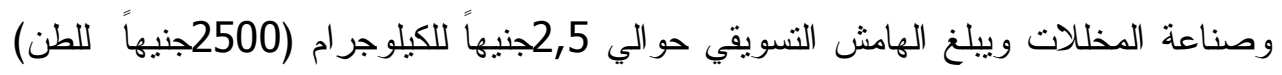




\section{جدول (8): مؤشرات الكفاءة التسويقية للصناعات الغذائية النباتية}

بعينة الدراسة الميدانية بمحافظة الثرقية خلا عام 2015.

\begin{tabular}{|c|c|c|c|c|c|c|c|c|c|}
\hline المتوسط & الوحدة & المؤشر & الصناعة & 5 & المتوسط & الوحدة & المؤشر & الصناعة & 5 \\
\hline 9,14 & جنيه/كجم & الكيلو جرام إنتاج & \multirow{8}{*}{ صناعة } & \multirow{8}{*}{3} & 9,07 & جنيه/كجم & الكيلو جر الم إنتاج & \multirow{8}{*}{ الفناعة } & \multirow{8}{*}{1} \\
\hline 14 & جنيه/كجم & سعر المنتج & & & 10,5 & جنيه/كجم & سعر المنتج & & \\
\hline 20 & جنيه/كجم & سعر البيع & & & 12 & جنيه/كجم & سعر البيع & & \\
\hline 6 & جنيه & التسويقي & & & 2,5 & جنيه & التسويقي الهامش) & & \\
\hline 70 & قرش ق & نصيب المنتج & & & 87,5 & قرش قر & في جيب المنتج & & \\
\hline 30 & قرش & نصيب التاجر & & & 12,5 & قرش & نصيب التاجر & & \\
\hline 4,86 & جنيه & صافي عائد & & & 1,43 & جنيه & صافي عائد & & \\
\hline 0,53 & جنيه & ربحية جنيه & & & 0,16 & جنيه & المستية جنيه (5) & & \\
\hline 10,45 & جنيه/كجم & الكيلو جر ام & \multirow{8}{*}{ تربية } & \multirow{8}{*}{4} & 9,40 & جنيه/كجم & الكيلو جر ام & \multirow{8}{*}{ المخلات } & \multirow{8}{*}{2} \\
\hline 17 & جنيه/كجم & سعر المنتج & & & 12,5 & جنيه/كجم & سعر المنتج & & \\
\hline 25 & جنيه/كجم & سعر البيع & & & 15 & جنيه/كجم & سعر البيع & & \\
\hline 8 & جنيه & التنسويقي & & & 2,5 & جنيه & التسويقي & & \\
\hline 68 & قرش & نصيب المنتج & & & 83,3 & قرش & في جنيب المنتج & & \\
\hline 32 & قرش & نصيب التاجر & & & 16,67 & قرش & في جيب التاجر & & \\
\hline 14,5 & جنيه & صافي عائد & & & 3,10 & جنيه & صافي عائد & & \\
\hline 0,63 & جنيه & ربحية جنيه & & & 0,33 & جنيه & ربحية جنيه & & \\
\hline
\end{tabular}

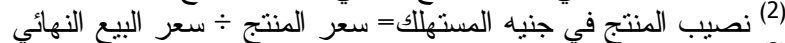

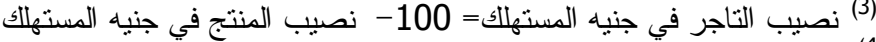

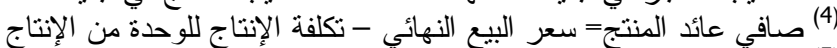

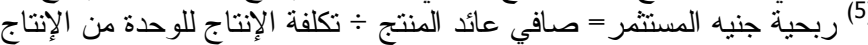
المصدر: حسبث من بيانات عينة الدر اسة الميدانية لعام 2015. 
(2) توزيع جنيه المستهلك بين المنتج والتاجر: من الجدول يتبين الآتي:

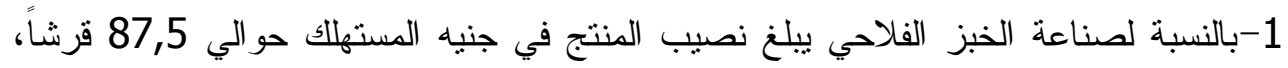

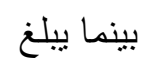

$$
\text { نصيب التاجر حو الي 12,5 قرشاً. }
$$

2-أما بالنسبة لصناعة المخلات فيلغ نصيب المنتج في جنيه المستهلك حوالي 83,3 قرشاً،

$$
\text { بينما بيلغ }
$$

$$
\text { نصيب التاجر حو الي 16,67 قرشاً. }
$$

3-أما فيما يتعلق بصناعة المربات فيلغ نصيب المنتج في جنيه المستهلك حو الي 70 قرشاً،

$$
\text { بينما يبلغ نصيب }
$$

$$
\text { التاجر حو الي } 30 \text { قرشاً. }
$$

4-و أخيراً بالنسبة لتربية و انتاج عيش الغراب فإن نصيب المنتج في جنيه المستهلك يبلغ حو الي

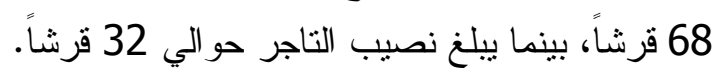

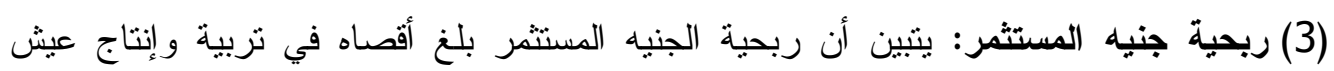

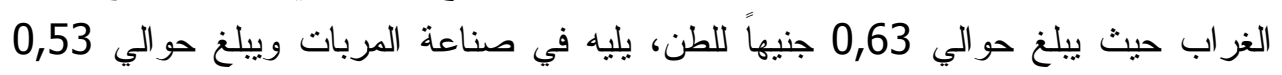

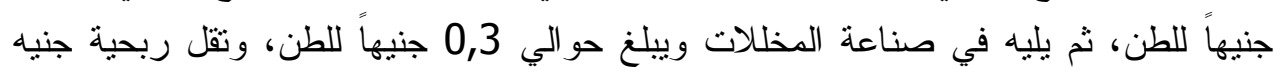

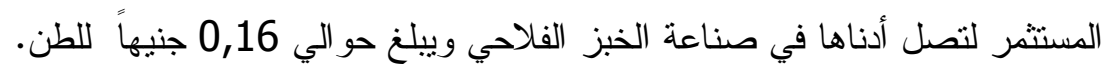
خامساً: دور التصنيع الزراعي في التنمية المستدامة(2):

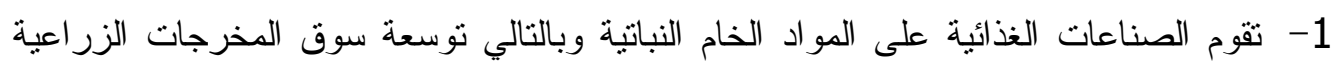
و الحفاظ على المستوى العام للأسعار أثناء فترات الإنتاج، وكذلك أثناء بيع المنتجات كبات كبديل

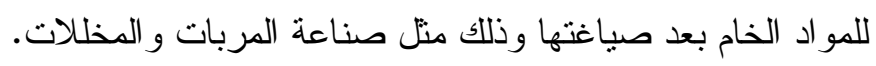

2- استخدام المخلفات الزراعية مثل قش الأرز و الذي يربى عليها عيش الغراب، ودئ ومصاصة

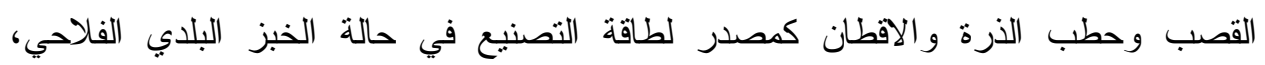
وبالتالي منع تلوث البيئة بحرق تلك المخلفات ويصبح لها مردود القتصادي. 3- تتشيط وتتغيل الصناعات الغذائية التحويلية بالريف منل صناعة طحن القمح و الذرة للحصول على الدقيق و الذي يستخدم في صناعة رغيف الخبز . 4- إتاحة فرص عمل جديدة و الحد من مشكلة البطالة عامة وشباب الخريجين والمرأة الريفية

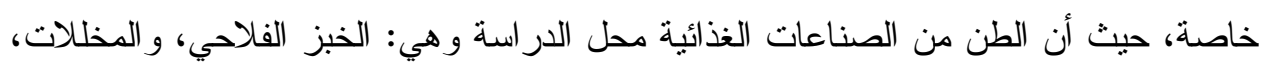
و المربات، وعيش الغراب تستوعب فرص عمل هن بواقع 25، 12، 10، 2 فرصة عمل لكل منها على الترتيب. 5- زيادة الدخل الأسري بالعمل في مجال التصنيع الزراعي الغذائي حيث يحقق الطن من الصناعات الأربعة صافي عائد حو الي 2925.35جنيه، 671.40 جنيه على التزتيب. 6- تشجيع قيام صناعات ثانوية معاونة ومكملة للصناعات الزر اعية الغذائية مثل صناعة الزجاج،

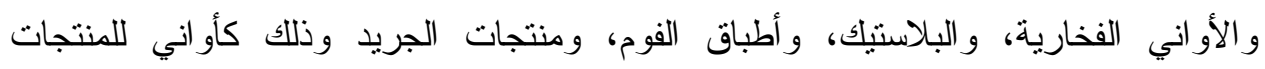
للصناعات موضع الدر اسة. 
7- نوفير احتياجات الريف من السلع المنتجة من نلك الصناعات منل الخبز الفلاحي و المخلات

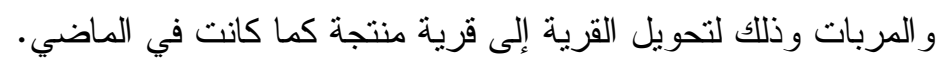

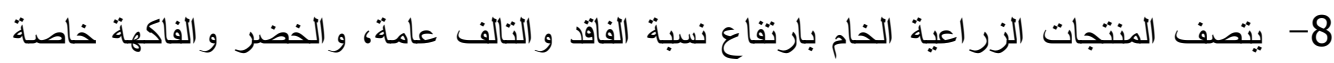

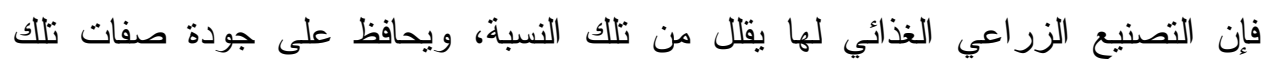
المنتجات.

\section{المراجع}

1- ابر اهيم سليمان ، محمد جابر : نظم التسويق الزراعي، دار الفكر العربي، الطبعة الأولى 2008

2- أحمد إحسان: التصنيع الزر اعي قاطرة التتمية المستدامة، جريدة مصر الزراعية (27 يونيو .(2012

3- الجهاز المركزي للتعبئة العامة والإحصاء، النشرة السنوية لاحصاء الانتاج الصناعي في

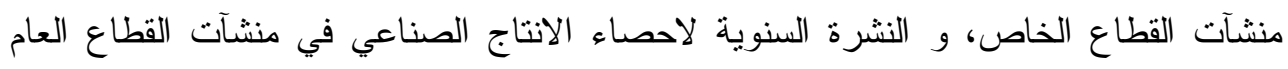
أعداد متقرقة. 4- إعتماد شعبان عثمان وآخرون : مخرجات الانتاج الزراعي وفرص استخداماتها في التصنيع

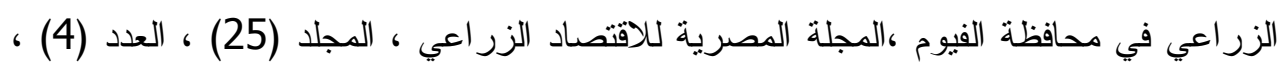

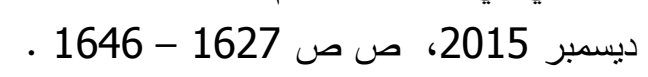
5- تقرير للجنة الصناعة و الطاقة بمجلس الثُب بعنوان: التصنيع الزراعي في مصر بين الواقع وطموحات المستقبل، 2009.

6 - حسن شعبان ، التتمية الريفية و الزر اعية في مصر ، جريدة مصر الزر اعية، 27 يونيه 2012.

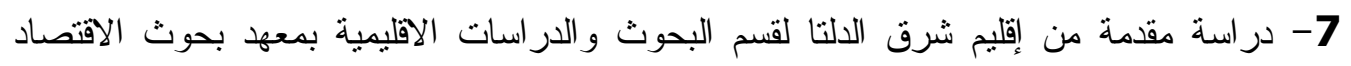

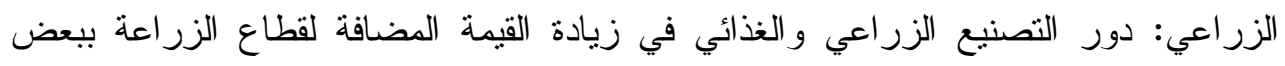

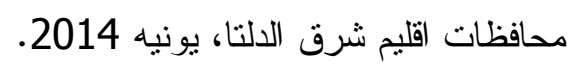

8-شحاته عبد المقصود غنيم و وآخرون : دور التصنيع الزراعي في زيادة القيمة المضافة لقطاع

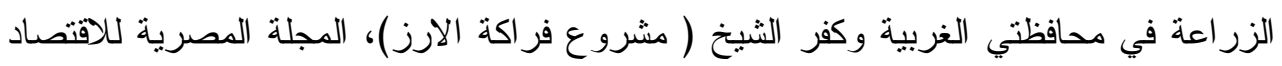

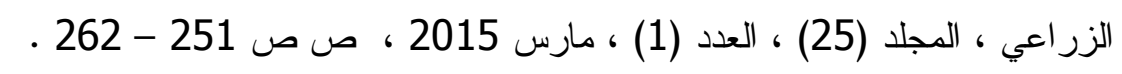
9-محمود محمود بدر : التقييم المالي والاقتصادي، محاضرات في قدم الاقتصاد الزراعي، كلية الزر اعة، جامعة بنها 2009. 10- وزارة الزراعة واستصلاح الأراضي، قطاع الثئون الاقتصادية، نشرة الدخل الزراعي، 2015 11 - وزارة الصناعة و التجارة الخارجية، قطاع المشروعات الصغيرة، مركز الاحصاء و المعلومات، وحدة در اسات الجدوى، بيانات غير منشورة . الملخص والتوصيات

يعتبر التصنيع الغذائي من أهم الوسائل لتطوير القطاع الزراعي وزئويات ولئدة القيمة المضافة للعديد

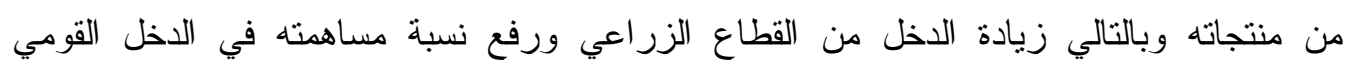

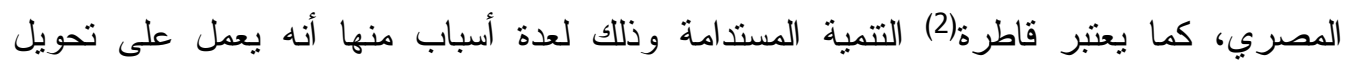


المنتجات الزر اعية الخام إلى منتجات وسلع غذائية مصنعة مما يؤدي إلى طول فترة الحفظ و الحد من

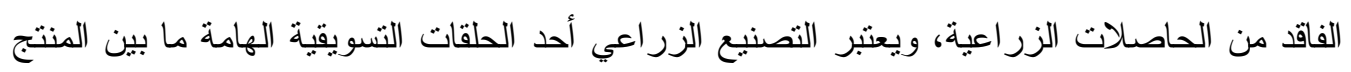

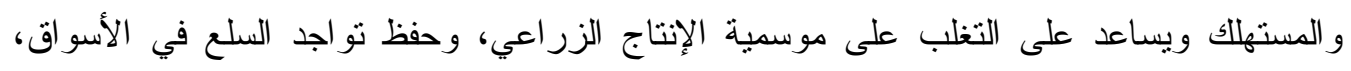
وبالتالي تو ازن أسعار السلع الزر اعية في الأسواق.

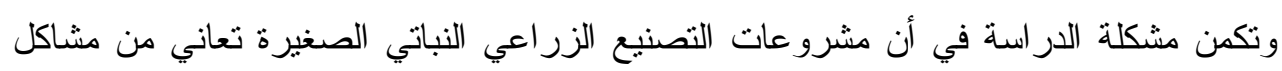

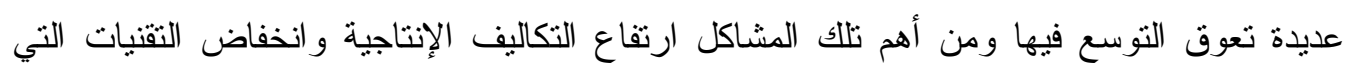

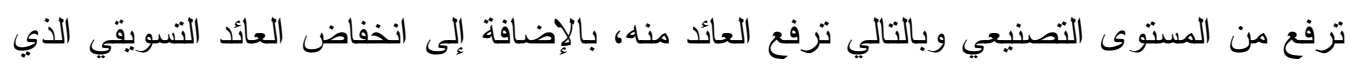

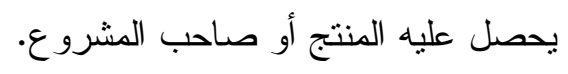
وتهدف الدر اسة إلى الارتقاء بمستوى التصنيع الزر اعي الغذائي النباتي وذلك من خلال دراسة

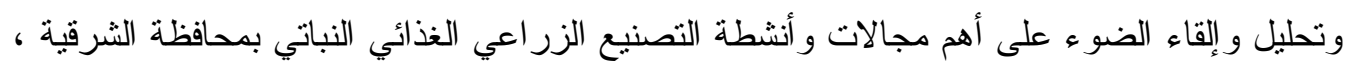

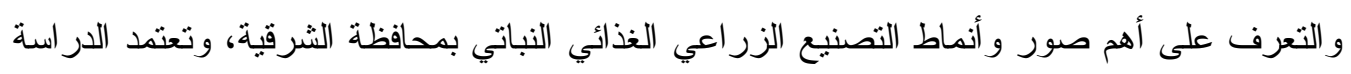
على الأسلوبين الوصفي و الكمي للبيانات. وتعتمد الدر اسة على مصدرين رئيسيين من البيانات وهما البيانات الثانوية من الجهاز المركزي ولئي

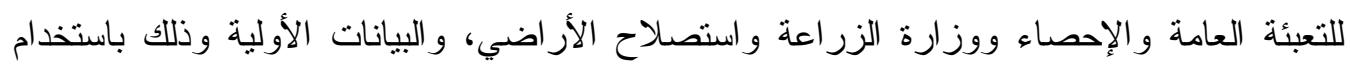

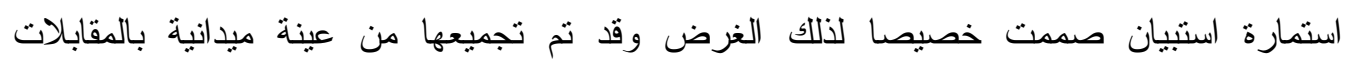

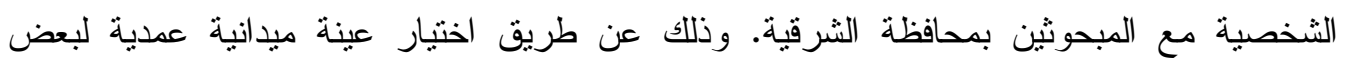

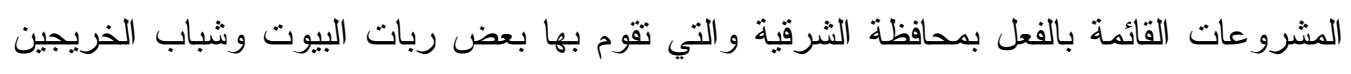

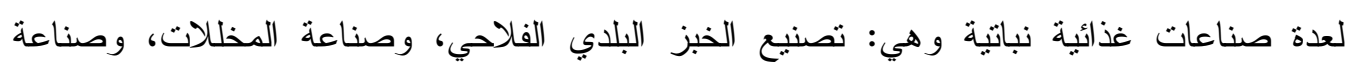

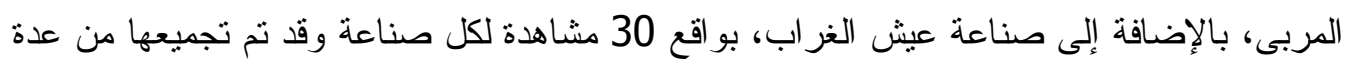
قرى ومدن بالمحافظة وبالتالي بلغ عدد المشاهدات 120 مشاهدة. وقد توصلت الدر اسة إلى عدة نتائج منها:

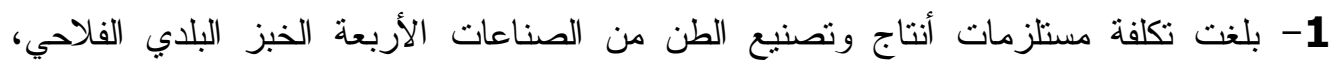

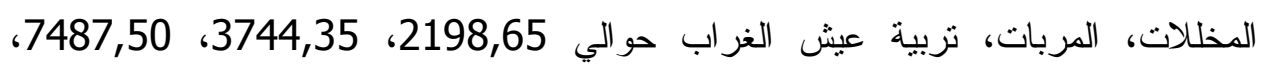
5870 جنيهاً للطن على الترتيب.

2- بلغت تكلفة طاقة النشغيل لإنتاج الصناعات الأربعة عيش الغر اب حيث بلغت حو الي 1855،

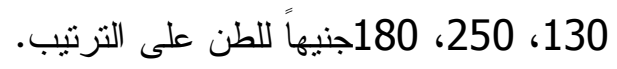

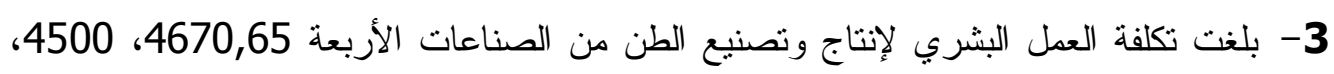

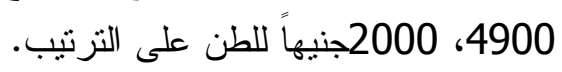
4- بلغت تكلفة إهلاك الآلات و الأدوات لإنتاج وتصنيع الطن من الصناعات الأربعة حوالي 80، 5- 62,08، 634,6 جنيهاً للطن على الترتيب. 6- وبدر اسة مؤشرات الكفاءة تبين الآتي: بلغت إجمالي التكاليف الإنتاجية لإنتاج وتصنيع الطن من الصني: الصناعات الأربعة حوالي 9074,65، 9404,45، 12099,55، 10284,6جنيهاً للطن على الترتيب. 
بلغت قيمة إير ادات الطن من المنتجات النهائية للصناعات محل الدراسة حوالي 12000،

، 12500

15000، 17000، 17500 جنيهاً للطن على الترتيب.

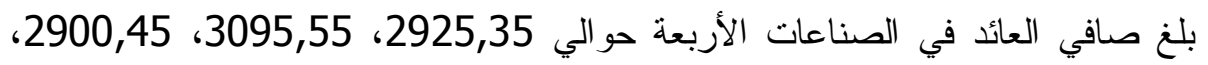
6715,40 جنيهاً للطن على الترتيب.

وبلغت ربحية الجنبه المستثمر في الصناعات الأربعة حوالي 0,32، 0,33، 0,24،

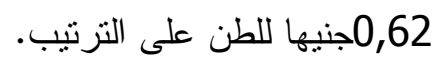
7- بدر اسة المؤشر ات التسويقية للصناعات الغذائية محل الدراسة تبين الآتي:

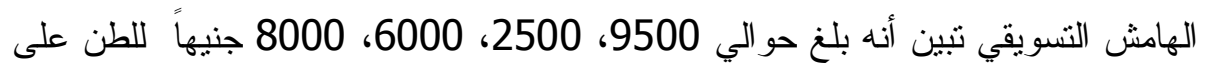
الترتيب.

بدراسة توزيع جنيه المستهلك بين المنتج و التاجر تبين أنه بلغ في صناعة الخبز الفلاحي

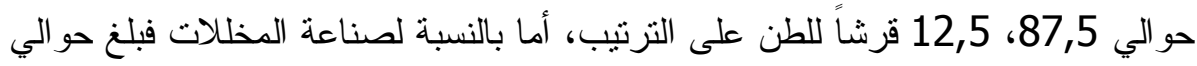

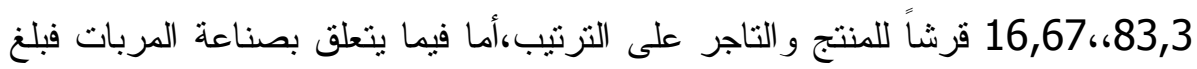

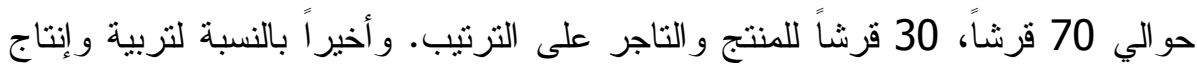

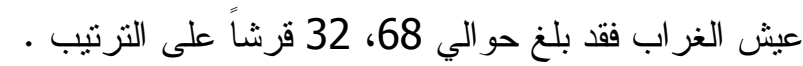

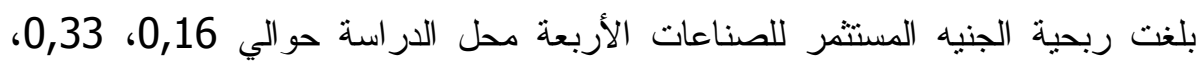

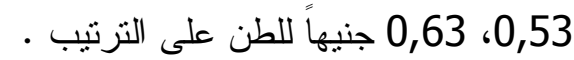
وبناءاً على ما سبق توصي الدراسة بالآتي :

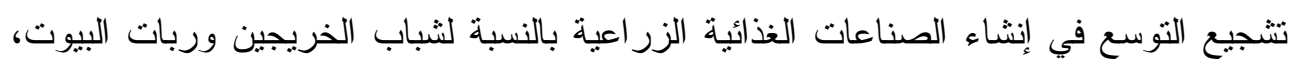

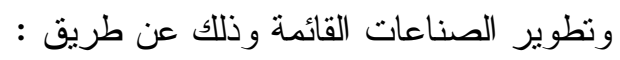
1- قيام الصندوق الاجتماعي للتنمية بنمويل نلك الصناعات وبقروض ميسرة تتمشي وظروف نلك

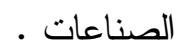
2- ربط القائمين بتلك الصناعات بالمر اكز البحثية وكليات ومدارس الزر اعة وذلك من خلال عمل

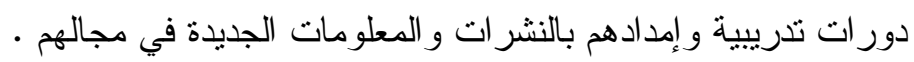

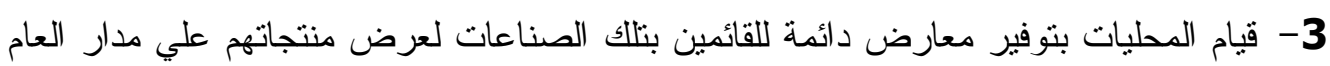
مقابل أجر رمزي وفي اماكن يقطنها السكان .

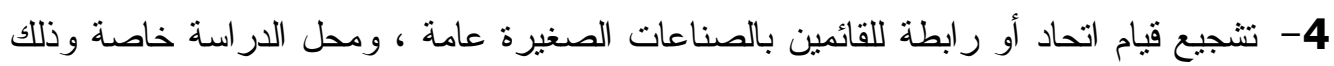
لعرض مشاكلهم علي المسئولين و إحداث نكامل فيما بينهم . 